Portland State University

PDXScholar

TREC Final Reports

Transportation Research and Education Center

(TREC)

$7-2018$

\title{
Survey of Oregon Electric Vehicle \& Hybrid Owners
}

John MacArthur

Portland State University, macarthur@pdx.edu

Michael Joseph Harpool

Portland State University

Daniel Scheppke

Portland State University

Follow this and additional works at: https://pdxscholar.library.pdx.edu/trec_reports

Part of the Transportation Commons, and the Urban Studies Commons

Let us know how access to this document benefits you.

\section{Recommended Citation}

MacArthur, John, Michael Harpool and Daniel Scheppke. Survey of Oregon Electric Vehicle \& Hybrid Owners. TREC-RR-1259. Portland, OR: Transportation Research and Education Center (TREC), 2018. https://www.doi.org/10.15760/trec.205

This Report is brought to you for free and open access. It has been accepted for inclusion in TREC Final Reports by an authorized administrator of PDXScholar. Please contact us if we can make this document more accessible: pdxscholar@pdx.edu. 
FINAL REPORT

Survey of Oregon Electric Vehicle \& Hybrid Owners

\section{TREC-RR-1259 July 2018}

TREC is the Transportation Research

and Education Center at Portland State University.

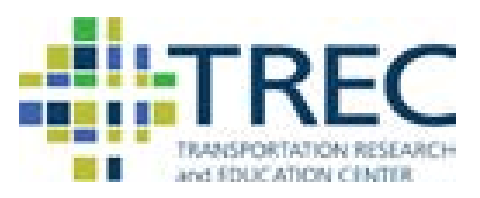





\section{SURVEY OF OREGON ELECTRIC VEHICLE \& HYBRID OWNERS}

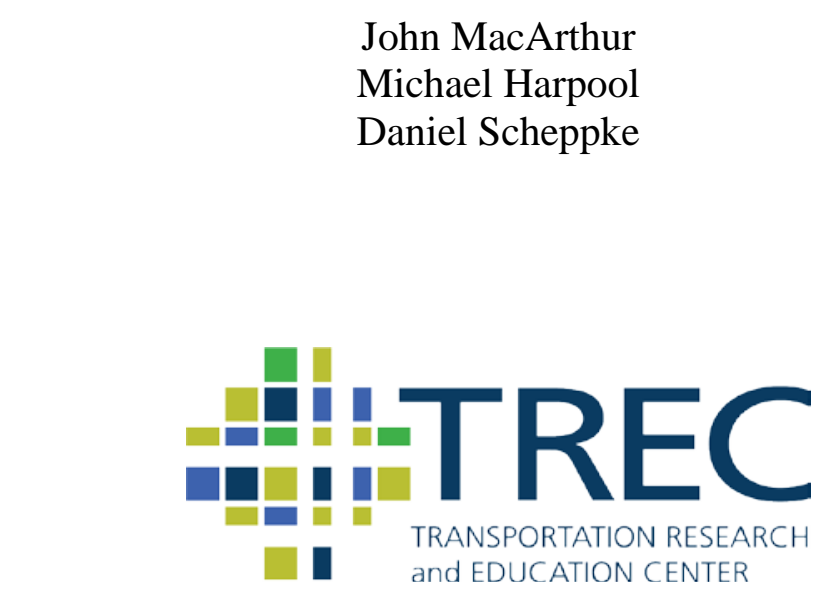

Transportation Research and Education Center (TREC)

\section{Portland State \\ UNIVERSITY}

Portland State University

P.O. Box 751

Portland, OR 97207

July 2018 



\section{ACKNOWLEDGEMENTS}

The authors would like to thank Forth for their valuable input, resources and support during the project to make sure it was successful. We'd like to thank all the respondents in Oregon for their time in taking the survey and their valuable input.

This project was funded through a grant from Metro's regional flexible funds through the Federal Highway Administration (FHWA) Congestion Mitigation/Air Quality Program.

Forth is a nonprofit 501(c)(6) trade association with a closely related 501(c)(3) charity, the Forth Mobility Fund. Forth works to advance electric, smart, and shared transportation in the Pacific Northwest and beyond through innovation and industry development; demonstration and pilot projects; policy advocacy; and consumer engagement.

\section{DISCLAIMER}

The contents of this report reflect the views of the authors, who are solely responsible for the facts and the accuracy of the material and information presented herein. Neither the State of Oregon nor the U.S. Government assumes no liability for the contents or use thereof. The contents do not necessarily reflect the official views of the U.S. Government. This report does not constitute a standard, specification, or regulation.

\section{RECOMMENDED CITATION}

MacArthur, John, Michael Harpool and Daniel Scheppke. Survey of Oregon Electric Vehicle \& Hybrid Owners. Portland, OR: Transportation Research and Education Center (TREC), 2018. 


\section{TABLE OF CONTENTS}

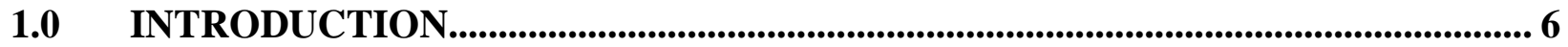

2.0 METHODOLOGY ..................................................................................................... 8

3.0 INTRODUCTION OF RESULTS............................................................................ 10

4.0 HYBRID AND ICE VEHICLE OWNERS ....................................................... 11

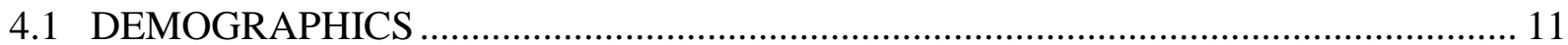



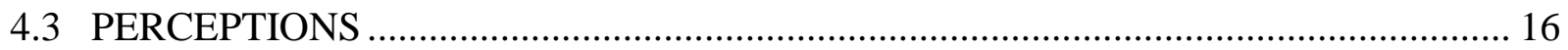

4.4 LIKELIHOOD TO PURCHASE AN ELECTRIC VEHICLE .......................................... 18

5.0 ELECTRIC VEHICLE OWNERS ……....................................................................... 25

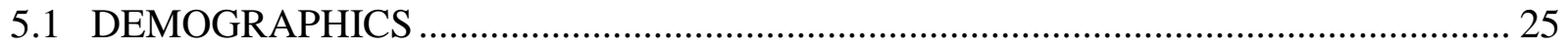

5.2 EV USE AND CHARGING BEHAVIOR ………….................................................... 27

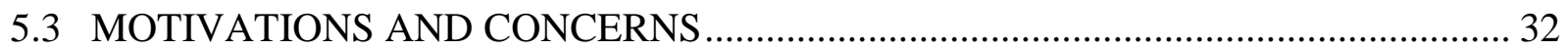

6.0 DISCUSSION ............................................................................................................... 42

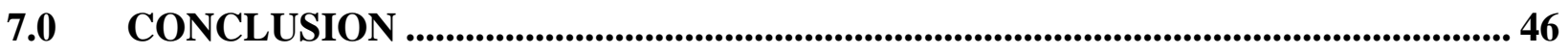

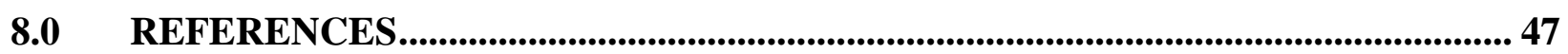

\section{LIST OF TABLES}

Table 1: Demographic Charateristics of Non-EV Owners ....................................................... 11

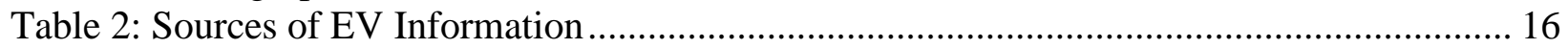

Table 3: Personal Opinions of Non-EV Owners........................................................................... 18

Table 4: Selected and Priortized Reasons Non-EV Owners Might Consider Purchasing an EV. 20

Table 5: Non-EV Owners' Selected and Priotized Concerns about Buying an EV ..................... 22

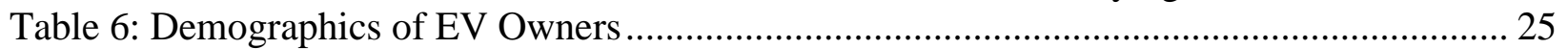

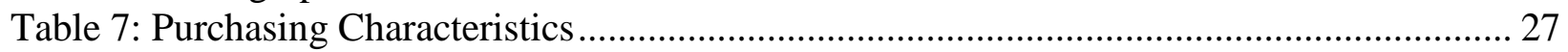

Table 8: Selected and Priortized Motivations for Buying an EV …………………....................... 33

Table 9: Selected and Priotized Concerns Before Purchasing an EV .............................................. 35

Table 10: Selected and Priortized Concerns After Purchasing an EV ........................................... 37

\section{LIST OF FIGURES}

Figure 1- Number of Registered EVs in Oregon (2010-2017) …............................................. 7

Figure 2: Non-EV Owners' Experience with EVs..................................................................... 13

Figure 3: Non-EV Owners' Perceptions about EV All-Electric Ranges (n=765-766) ................... 14

Figure 4: Non-EV Owners’ Perceptions about EV Charging Duration (n=756-757) ..................... 14

Figure 5: Non-EV Owners' Familiarity with EVs (n=777-778).................................................... 15

Figure 6: Non-EV Owners' Perceptions of EVs (n=771-778) ...................................................... 17

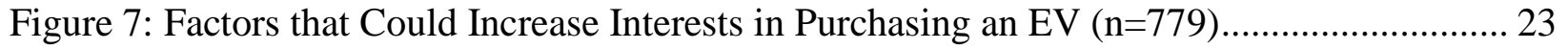

Figure 8: Liklihood to Purchase Fuel-Efficient Vehicles (n=760-761) ......................................... 24

Figure 9: Miles Driven in a Typical Day by Urban/Rural Land Designation .............................. 28 
Figure 10: Charging Frequency 28

Figure 11: Percent of Charging that Takes Place at Each Location $(n=3,278-88)$..................... 30

Figure 12: Satisfaction with Public Charging Infrastructure ............................................... 31

Figure 13: Importantance of Public Charging Infrastrcuture Improvements............................. 32

Figure 14: Comparing Pre- and Post-Purchase Concerns of EV Owners (n=3,230-38) ............. 39

Figure 15: Satisfaction with EV Attributes.................................................................... 41

Figure 16: Motivations of Non-EV owners and EV-Owners Compared................................... 43

Figure 17: Comparing the Concerns of Non-EV Owners to Those of EV Owners.................... 45 


\section{EXECUTIVE SUMMARY}

The market for electric vehicles (EVs) is changing dramatically in the United States. Federal and state policies have been adopted to promote research and development in EV technology and to increase the number of EVs available in order to support increasing rates of EV ownership. The state of Oregon has one of the highest per-capita EV sales markets in the country. However, much is to be done if Oregon is to reach its ambitious goal of complete electrification of the private automobile industry by 2050. The goal of this study is to illuminate some of the current challenges and opportunities EV automakers and policy decision-makers are presented with in this rapidly changing market. To do this, the researchers utilize survey results received from individuals who currently own or lease an EV (plug-in hybrid electric vehicle (PHEV) or battery electric vehicle (BEV)) or other low-carbon vehicle (hybrid vehicle). These groups are first analyzed separately. For each analysis, results are disaggregated by vehicle type and land designation (urban/rural) to illuminate similarities, differences, and trends across populations. Then the results from the two surveys are compared in order to reveal commonalities between EV owners and owners of other low-carbon vehicles.

Hybrid and other internal combustion vehicles (i.e. ICE) vehicle owners demonstrated a fairly high degree of familiarity with EVs, and many reported that they have the desire to learn more. Approximately half of the respondents felt that EVs are convenient vehicles, and the vast majority were in favor of EVs replacing gas vehicles over time (82.3\%). However, the results indicate that within the existing conditions the average respondent's next vehicle is most likely to be a hybrid. Thus, it is evident that their motivations for purchasing an EV are currently outweighed by their concerns. In terms of motivations, non-EV owners prioritized the desire to reduce their driving's impact on the environment, save on the cost of fuel, and reduce the amount of oil imported into the United States. ICE owners and rural residents appear to be less motivated by reducing their driving's effect on the environment and the amount of oil imported into the United States. The most important concerns for these individuals included the perception that EVs are not convenient for long trips, the fear of running out of charge and getting stranded, and the lack of sufficient public charging infrastructure. The primary concerns were fairly similar between respondents who owned a hybrid and an ICE vehicle and between urban and rural residents; however, ICE owners tend to be more concerned with the convenience for long trips and less concerned with the current status of public charging infrastructure.

EV owners demonstrated a high level of satisfaction with their vehicles; however, most respondents were not satisfied with the quality of the public charging experience. While there was a fair share of rural residents who owned an EV, they were far less likely than urban residents to rely on their EV for the majority of their daily driving, and they tend to drive a significantly greater number of miles each day. EV respondents cited the reasons which motivated them to purchase their vehicle. The most common motivations were the desire to reduce their driving's impact on the environment, wanting to save on the cost of fuel, and interest in the new technology. Again, disaggregating these results by vehicle type (BEV and PHEV) and land designation highlighted significant differences. With respect to the primary motivations, $\mathrm{BEV}$ owners were less likely to be motivated by savings on fuel costs and more so by their interest in the new technology. On the other hand, rural residents attributed less importance to their contribution to the environment and were more strongly motivated by the desire to save on 
fuel costs. EV respondents also reported the concerns that they had before purchasing an EV as well as those that they had afterwards. The most important pre-purchase concerns were related to sufficiency of the battery range, the performance of the battery over the life of the vehicle, and the fear of running out of charge and getting stranded. The former two remained the most important post-purchase concerns, although consensus dropped significantly. The fear of running out of battery and getting stranded fell far below the top three, and was replaced by concern about public charging infrastructure. For both sets of concerns, results differed significantly between PHEV and BEV owners. Most notably, PHEV owners were far less likely to be concerned about battery range and getting stranded, yet they were more concerned with the performance of the battery over the life of the vehicle. Surprisingly, rural residents were significantly less likely than urban residents to cite range anxiety as a primary concern. Overall, the assessment of concerns before and after the purchase of an EV revealed battery range may not be as important of a concern as a potential buyer may believe; however, other concerns, such as the presence of public charging infrastructure, may become more important.

While analyzing responses from EV owners and non-EV owners separately provided useful insight into the perceptions and behaviors of these groups, comparing the two could serve as a valuable tool for valuing non-EV owners' propensity to purchase an EV and advocating for EVs more generally. Despite a few slight differences, EV and non-EV owners prioritized similar motivations and concerns. In terms of motivations, both EV and non-EV owners highly valued their desire to reduce their driving's effect on the environment, save on the cost of fuel, reduce the amount of oil imported into the United States, and their interest in the new technology. Primary concerns about battery sufficiency and range anxiety also aligned across groups. These similarities provide important information about potential EV consumers, and the relatively dramatic reductions in concerns post-purchase could be used to help push individuals in the market for a new car towards EVs. For example, the considerable decrease in primary concerns could be a useful illustration for those who may be deterred by concerns about battery range and longevity. On the other hand, the increased concern about charging infrastructure suggests that measures should be taken to enhance public charging. These improvements are especially important for individuals lacking the ability to charge at home. While the majority of respondents in this sample lived in a single-family detached home with the option to charge, many urban residents who rely on street parking may not have access to secure charging; thus, owning and operating an EV for daily mobility needs may not be feasible.

This study suggests that the majority of EV owners in Oregon are white, well-educated, and affluent. In order for EVs to gain widespread acceptance there is a necessity to endorse educational programs in low-income minority communities and provide incentives to support socioeconomically disadvantaged households. Future research could provide important insight into the social and economic barriers to purchasing an EV. Other avenues for research include exploring the rather dismal presence and influence of work incentives, examining the changes in travel behavior before and after purchasing an $\mathrm{EV}$, and investigating the significance of EVs in rural households. 


\subsection{INTRODUCTION}

The past several years have seen dramatic disruption in the traditional automotive industry, especially with emerging alternative fuel-source vehicles. Electric vehicles (EVs), which were barely available just eight years ago, are now available in a wide array of makes and models throughout the country.

Sales of EVs grew rapidly from 2011 to 2017. Technology improvements, battery cost reduction, increasing model choice, maturing charging infrastructure, and economic recovery have continued to influence and support increased sales. In 2017, approximately 200,000 electric vehicles were sold in the U.S., which is an increase of 40,000 EVs from 2016 (1). The Nissan Leaf and Chevrolet Volt have been available on the market the longest and have the largest overall sales, and the Tesla Model S continues to be the best-selling plug-in electric vehicle (PEVs, including BEVs and PHEVs) in the U.S. These three models accounted for over half of all PEV sales in 2015-2017.

California is the largest U.S. market for both hybrid and EV sales, making up 33\% of total sales. Hybrids made up 66\% of the total U.S. sales in 2017. These sales are not evenly distributed globally, or within the United States. Some states have very few or no electric vehicles registered. In other regions as much as $10 \%$ of new vehicles sold are electric. EVs make up around $2 \%$ of new sales in Oregon, making it one of the highest per-capita sales markets in the country. In the U.S. there is a clear gradual shift away from hybrids to both gas/diesel vehicles and to EVs. In 2013, California had 536,000 hybrids sold but in 2017 that number was down to 365,000 (2). Some of this shift is caused by market availability, shifts in incentives towards $\mathrm{ZEVs}$, and the continued low gas prices.

Oregon has a population of 4.1 million and ranked 41th in U.S. population density. Approximately $70 \%$ of the state population (2.9 million people) live in the Willamette Valley - a region approximately 150 miles long and 40 miles wide stretching south from the state's major cities, Portland, Salem and Eugene. Oregon had approximately 3.5 million registered passenger vehicles in 2017, of which 1.4 million were in the Portland metro region (3). In 2016, the total sales of new passenger vehicles in Oregon was 185,258 with 35.8\% cars, 41.7\% SUVs, $16.9 \%$ pickups and 5.6\% vans. Of those vehicles 3.7\% were hybrid, $1.1 \%$ battery electric vehicles (BEV) and 0.8\% plug-in hybrid electric vehicles (PHEV) (4). Oregon has some of the cheapest and lowest carbon electricity in the U.S., due in large part to its large hydroelectric utility system. Residential electricity rates in Oregon average $8.83 \$ / \mathrm{kWh}$, which ranks the state 39th in the nation. About 70\% of Oregon's power comes from clean and renewable sources (5). Figure 1 shows the number of registered EVs in Oregon from 2010 to 2017, showing 92\% growth over the last two years. 


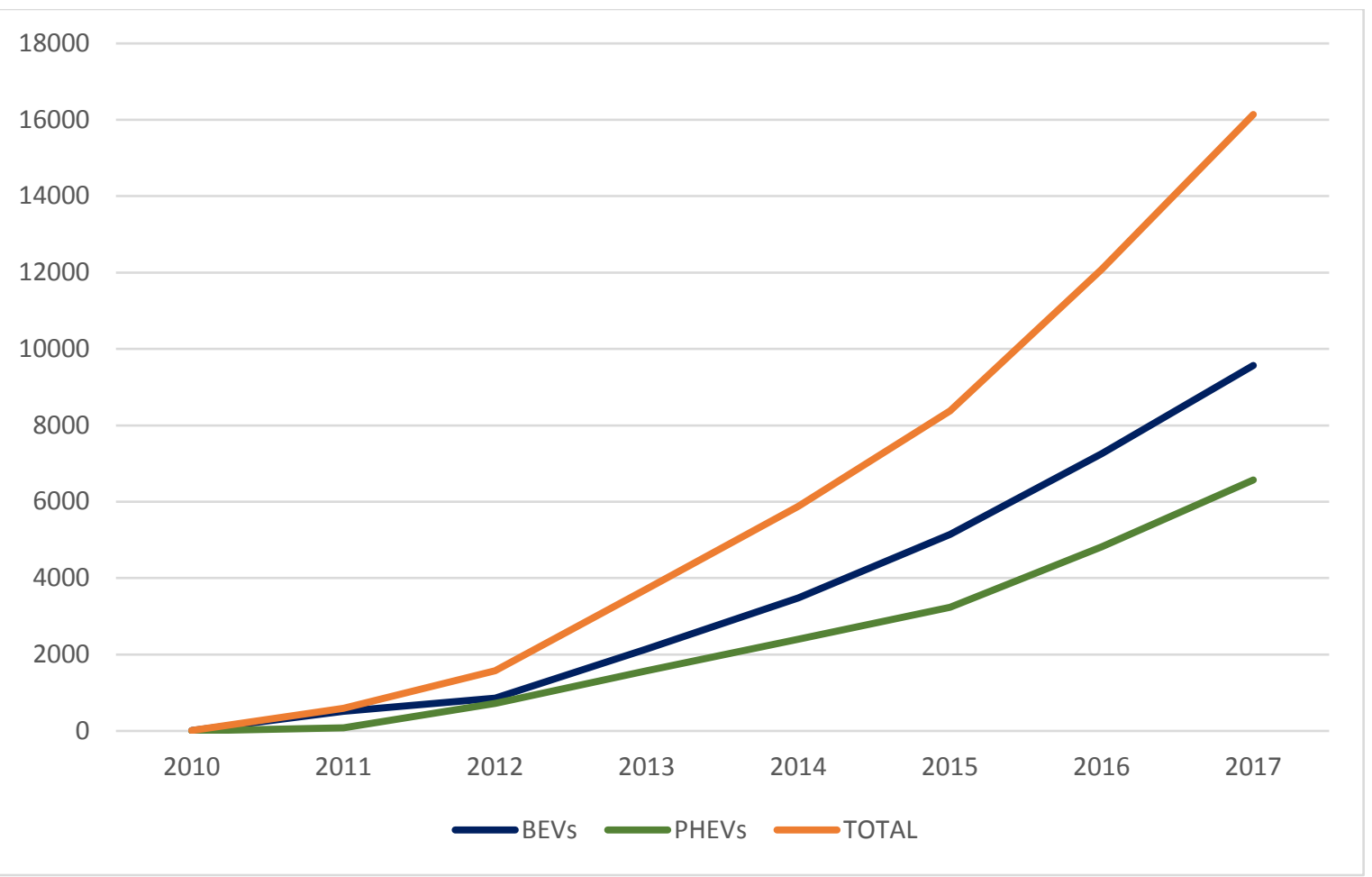

Figure 1- Number of Registered EVs in Oregon (2010-2017)

While EV sales are growing, the state hopes to meet long-range greenhouse goals and EV adoption goals. Oregon is one of nine states that has adopted the Zero Emission Vehicle (ZEV) Mandate in 2006 developed in California, which requires approximately 15\% of new vehicle sales in 2025 to be zero-emission vehicles. Oregon has also joined the International ZEV Alliance, other state and national governments, in a more ambitious goal of having all new cars sold be zero-emission electric vehicles by 2050 (6). In 2016, Oregon passed legislation that doubles the state's Renewable Portfolio Standard to 50\% and bans the sale of electricity produced by burning coal, while requiring electric utilities to develop plans to accelerate transportation electrification. In August 2017, Oregon Governor Kate Brown signed HB 2017, which establishes a program to provide rebates of up to $\$ 2,500$ for people who purchase certain types of electric vehicles (including plug-in hybrid electric vehicles) and other qualifying zeroemissions vehicles (7).

Oregon has one of the most extensive EV public charging networks in the U.S. with over 1,000 Level 2 chargers and more than 125 DC quick-chargers, allowing drivers to charge on the go and extend their driving range (8). 


\subsection{METHODOLOGY}

The goal of the study was to learn from people living in Oregon who either own an electric vehicle or hybrid vehicle about their views on electric vehicles and their experiences purchasing, owning and driving their vehicle.

The study consisted of two online surveys. One survey was for hybrid vehicle owners and included questions about their knowledge and perceptions of electric vehicles. The second survey was for electric vehicle owners and included questions about their experiences owning their vehicles. A modified version of the hybrid vehicle-owner survey was available for households that were contacted but did not own a hybrid vehicle or an electric vehicle. The survey methodology was approved by PSU's Human Subjects Research Review Committee (HSRRC).

A draft survey was developed by the research team by reviewing similar studies conducted on consumer perceptions of electric vehicles. The research team and partners then reviewed the draft questions, which underwent several rounds of revisions. Certain questions were consistent between the two surveys, including a number of general questions about travel behavior, demographics and perceptions of electric vehicles.

The electric vehicle-owner survey consisted of 62 questions covering a range of topics related to drivers' experiences with their electric vehicles organized into six sections. The first section contained questions about the characteristics of respondents' electric vehicles. The second section asked about travel behavior. The third section had questions about vehicle charging habits. The fourth section contained questions about experiences purchasing an electric vehicle. The fifth section asked participants to share what they currently like and dislike about their vehicles. The last section was demographic questions.

The hybrid vehicle-owner survey asked respondents 57 questions about their knowledge, awareness, and perceptions of electric vehicles and was organized into five sections. The first section contained questions about respondents' driving habits. The second section was a test of respondent's knowledge about electric vehicles. The third section was about perceptions of electric vehicles. The fourth section asked participants about their plans for their next vehicle purchase. The last section was demographic questions.

Participants were selected from a list from the Oregon Department of Transportation Driver and Motor Vehicle (DMV) Services, which included contact information for all households in Oregon that had registered an electric vehicle or hybrid vehicle. We randomly selected 8,000 households that had registered a hybrid vehicle to participate in the study. Every household that had registered an electric vehicle since 2010 was invited to participate. Contact information was checked using a U.S. Postal Service database to remove invalid households. In total, 8,000 households that had registered a hybrid vehicle and 11,476 households that had registered an electric vehicle in Oregon were asked to participate in the study. 
The survey was administered online and was open from June 10 to July 31. Households received a letter that invited them to take the survey. Two weeks later, households received follow-up postcards that reminded them to take the survey. To encourage people to participate in the study, participants were given an opportunity to enter into a prize drawing for ten \$50 Amazon gift certificates upon completion of the survey.

Closed-end responses were analyzed with SPSS statistical software to identify trends and differences. The survey included several questions that gave respondents the opportunity to include open-ended text responses. These responses were analyzed, coded and grouped by major theme, where possible. For groupings difference — vehicle type and land designations—we calculated standardized adjusted chi-square residuals in SPSS. By convention, residuals with absolute values of two or greater indicate a likely statistically significant $(\mathrm{p}<=0.05)$ difference for a group. 


\subsection{INTRODUCTION OF RESULTS}

A total of 19,476 survey invitation letters were sent out to randomly selected households, 879 of which were returned because of an incorrect address or designated "return to sender." Of the remaining 18,597 letters, 4,436 online survey responses were recorded. This represents an initial response rate of $23.8 \%$. The 4,436 survey responses included 3,565 households with EVs, 812 with a hybrid or other internal combustion vehicles (i.e. ICE), and 59 with no reported vehicle type. Though ICE owners were not targeted, some people no longer had a hybrid or only responded about the ICE vehicle they currently own. After careful consideration, 367 responses were removed from the analysis: 275 EV responses, 33 hybrid/ICE responses, and all 59 responses that did not report a vehicle type. These respondents were removed based on limited survey progress. In order for a response to be included for analysis the participant had to complete the question where they were asked to select three reasons they might consider purchasing an EV (non-EV owners) or decided to purchase an EV (EV owners). This was equivalent to 33\% progress for non-EV owners and 70\% for EV owners. After removal, 4,069 total responses remained (22\% response rate), which consisted of 3,290 EV responses and 779 non-EV responses.

The findings of this study are presented in two distinct sections. The first section presents the results from the hybrid owner survey. The primary goals of this section are to: identify the demographic characteristics of hybrid and ICE owners; understand their current awareness of and familiarity with EVs; illuminate the ways EVs are perceived by non-owners; and highlight the key concerns about purchasing an EV and the reasons an individual might consider purchasing one. The latter goal focuses on identifying differences and trends within the data as well as across populations. The results are disaggregated by the type of car respondents owned (hybrid and ICE vehicle) and land designation (urban and rural). Statistical analysis is utilized to highlight significant differences in the factors these populations are motivated by and the concerns that they prioritize.

The second section presents the results of the EV owner survey. This section is guided by three goals, which include: identify the demographic characteristics of EV owners; provide insight into the travel behavior and charging habits and identify whether they differ by EV type (BEV and PHEV) or land designation; and to compare motivations for purchasing an EV and concerns about owning an EV across populations. Respondents reported the concerns that they had before purchasing their electric vehicle and those that exist post-purchase. Pre- and post-purchase concerns are compared to illuminate how the importance of concerns may change after owning and driving an EV.

The discussion section highlights key findings, but also compares the results of the two surveys. Comparing these groups can be useful for identifying opportunities for enhancing EV ownership. Highlighting similarities in motivations could suggest whether or not hybrid and ICE vehicle owners are a potential population to prioritize in EV advocacy. Moreover, a better understanding of the primary concerns considered by non-EV owners could guide future public policy, outreach and awareness, and investment as it relates to incentivizing EV ownership. 


\subsection{HYBRID AND ICE VEHICLE OWNERS}

This section explores the survey responses of non-EV owners. These respondents owned or leased a hybrid or an ICE vehicle. After demographic characteristics are presented, the respondents' awareness and perceptions of EVs are assessed, followed by an examination of certain attributes that may impact their decision to purchase an EV in the future. The latter component consists of the reasons non-EV owners might consider purchasing an EV as well as their concerns for buying an EV. Results are disaggregated by vehicle type (hybrid and ICE) and land designation (urban and rural) to highlight similarities and differences between groups.

\subsection{DEMOGRAPHICS}

Table 1: Demographic Charateristics of Non-EV Owners

\begin{tabular}{|c|c|c|c|c|}
\hline & \multicolumn{4}{|c|}{ Percentages by Group } \\
\hline & $\begin{array}{c}\text { All } \\
\text { Respondents }\end{array}$ & Non-EV & ICE & Hybrid \\
\hline Own or lease a vehicle & $\mathrm{n}=4069$ & $\mathrm{n}=779$ & $n=124$ & $\mathrm{n}=655$ \\
\hline & 100.0 & 19.1 & 16.1 & 3.0 \\
\hline Race & $n=3925$ & $\mathrm{n}=758$ & $\mathrm{n}=120$ & $\mathrm{n}=638$ \\
\hline American Indian or Alaska & & & & \\
\hline Native & 0.6 & 0.3 & 0.0 & 0.3 \\
\hline Asian & 4.0 & 2.6 & 0.8 & 3.0 \\
\hline Black or African American & 0.5 & 0.4 & 1.7 & 0.2 \\
\hline Hispanic or Latino/a & 1.6 & 1.6 & 1.7 & 1.6 \\
\hline White or Caucasian & 89.1 & 91.8 & 92.5 & 91.7 \\
\hline Other & 4.3 & 3.3 & 3.3 & 3.3 \\
\hline Age & $n=3906$ & $\mathrm{n}=756$ & $\mathrm{n}=118$ & $\mathrm{n}=638$ \\
\hline $18-24$ & 0.7 & 1.9 & 0.8 & 2.0 \\
\hline $25-34$ & 7.3 & 9.7 & 8.5 & 9.9 \\
\hline $35-44$ & 18.4 & 14.2 & 17.8 & 13.5 \\
\hline $45-54$ & 22.6 & 17.9 & 23.7 & 16.8 \\
\hline $55-64$ & 25.3 & 26.3 & 25.4 & 26.5 \\
\hline $65+$ & 25.8 & 30.2 & 23.7 & 31.3 \\
\hline Gender & $n=3935$ & $\mathrm{n}=762$ & $n=120$ & $n=642$ \\
\hline Male & 65.3 & 56.8 & 65.0 & 55.3 \\
\hline Female & 34.2 & 42.8 & 34.2 & 44.4 \\
\hline Other & 0.5 & 0.4 & 0.8 & 0.3 \\
\hline
\end{tabular}

$\begin{array}{lcccc}\text { Education } & \mathrm{n}=3955 & \mathrm{n}=763 & \mathrm{n}=121 & \mathrm{n}=642 \\ \text { High school or less } & 1.8 & 2.0 & 2.5 & 1.9 \\ \text { Some college, no degree } & 13.5 & 12.8 & 14.9 & 12.5 \\ \text { Associate's degree } & 5.8 & 4.8 & 6.6 & 4.5\end{array}$




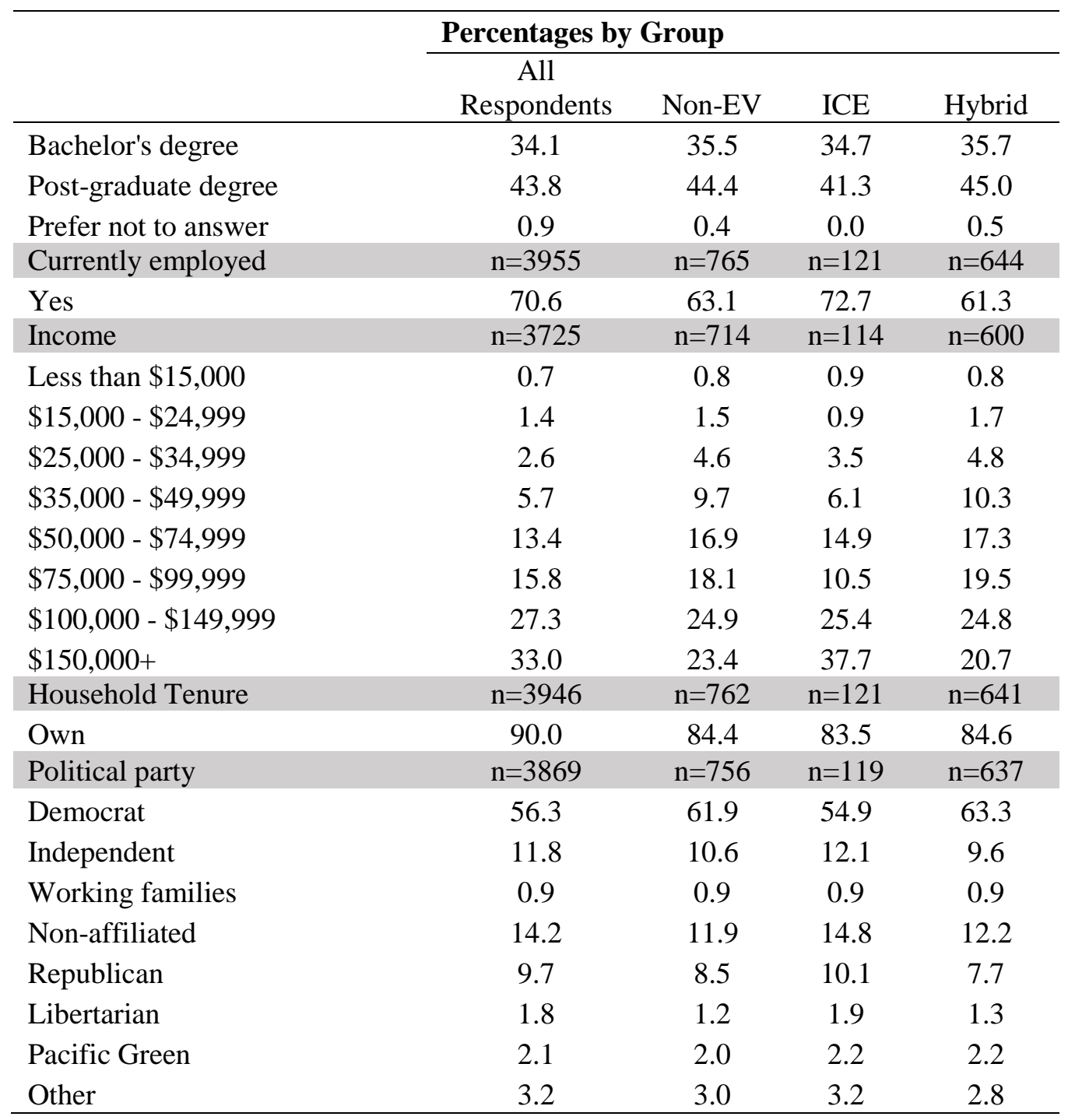

Table 1 provides a summary of selected demographic characteristics. Respondents of this survey were predominately white (89.1\%), male (65.3\%), older than 55 (51.1\%), employed (70.6\%), held a bachelor's degree or higher (77.9\%), and had an annual household income over \$100,000 (50.3\%). The majority also owned their home (90\%), identified with the Democratic political party (56.3\%), and were married or live with a partner (84.7\%). Hybrid or ICE vehicle owners make up about $19 \%$ of the total sample. When compared to the average, including EV respondents, these groups had greater proportions of white (91.8\%), highly educated (79.9\%), older (56.5\%), and Democratic respondents (61.9\%). They had lower proportions of male (56.8\%), high-income (48.3\%), home-owning (84.4\%), and employed respondents (63.1\%).

Respondents provided additional characteristics not listed in the table. Of the employed hybrid and ICE respondents, 89.8\% worked outside of their home. When compared to the average (87.9\%), these respondents were less likely to live in a single-family detached home (81.1\%). Respondents' ZIP codes were classified as urban or rural using the Oregon Office of Rural Health's land designation data set; 83.8\% of hybrid and ICE respondents lived in areas designated as urban. ICE vehicle owners were more likely to live in rural areas (21.1\%) than 
hybrid owners (15.3\%). Nearly all of the respondents from both surveys owned a smartphone (95.3\%); ICE owners were more likely to own a smartphone (97.5\%) than hybrid owners (93.8\%). With respects to vehicle ownership, Toyota was the by far the most popularly owned make of hybrid; of the 655 hybrid respondents, 497 or $75.9 \%$ reported that their primary hybrid vehicle was made by Toyota. Approximately 18\% of the hybrids were made in 2015 or later, 44.3\% were 2010-2014 models, and 38.1\% were made before 2010 .

\subsection{AWARENESS}

A variety of questions were deployed to assess hybrid and ICE vehicle owners' awareness of and knowledge about electric vehicles. Nearly one-third of these respondents have been a passenger in an EV (30.2\%), a quarter of them have driven an EV (25.2\%), and most have seen EVs on the road or in parking lots (74.3\%). Of those who have been a passenger, the majority reported having been a passenger in an EV 1-5 times, while those who have driven an EV were most likely to report doing so more than 25 times (Figure 2). Approximately $86 \%$ of respondents reported that they notice public EV charging stations during their regular weekly activities. Many respondents also declared that they have a family member, friend, or colleague who owns an EV (59.4\%).

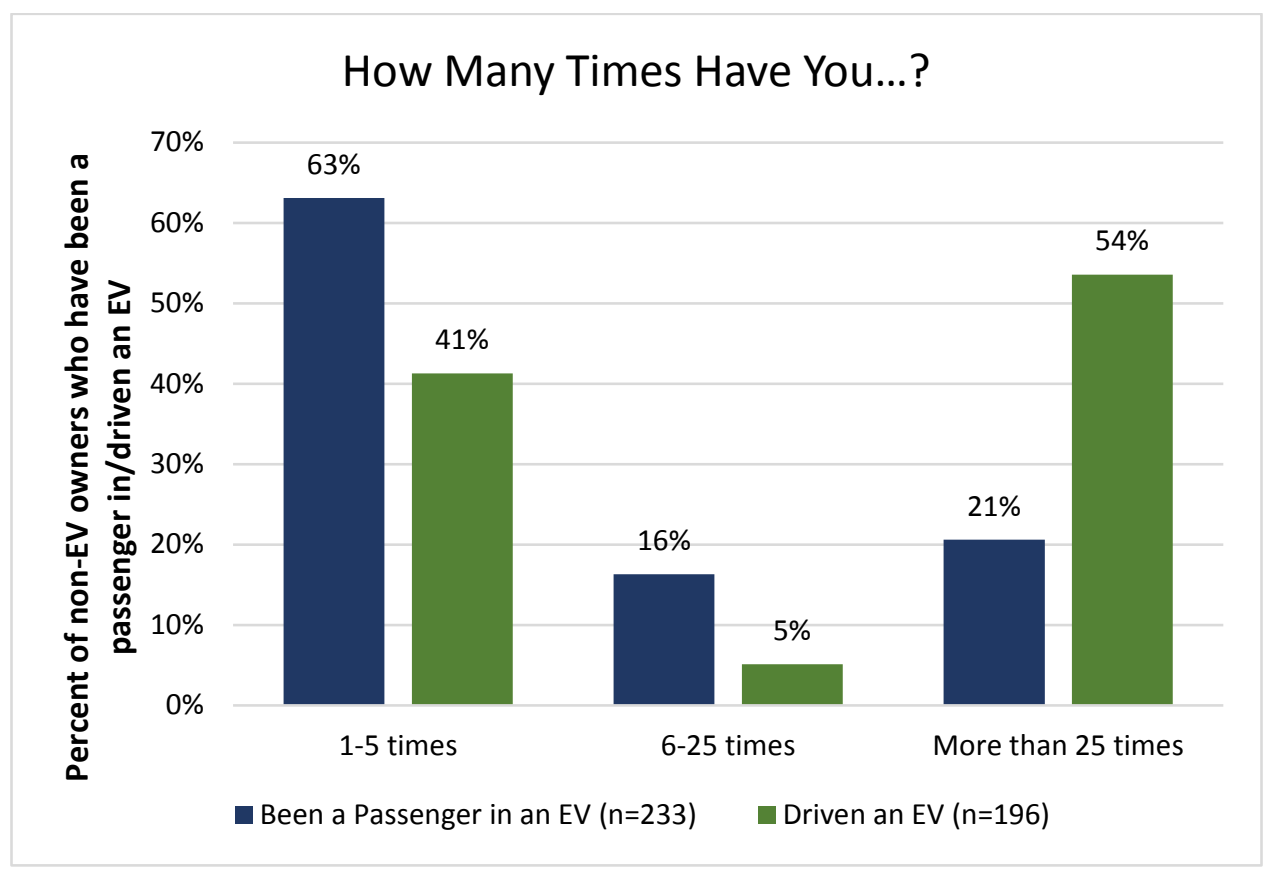

Figure 2: Non-EV Owners' Experience with EVs

A short list of questions was used to test the respondents' knowledge and to provide insight into their perceptions of how EVs function. Figure 3 shows their understanding about the all-electric ranges of plug-in hybrid electric vehicles (PHEVs) and battery electric vehicles (BEVs). The results demonstrate that the majority of individuals believe that BEVs have greater all-electric ranges than PHEVs; 46.9\% reported PHEVs have all-electric ranges greater than 100 miles and $67.3 \%$ reported BEVs have all-electric ranges greater than 100 miles. Figure 4 shows their understanding of how long it takes to charge EVs utilizing different types of chargers, Level 2 chargers and DC fast chargers. Respondents generally feel that DC fast chargers charge EVs (0 
to $80 \%$ ) faster than Level 2 chargers (0 to 100\%). Respondents were also asked if all electric vehicles can be charged with DC fast chargers; about 30 percent believed that this was a possibility.

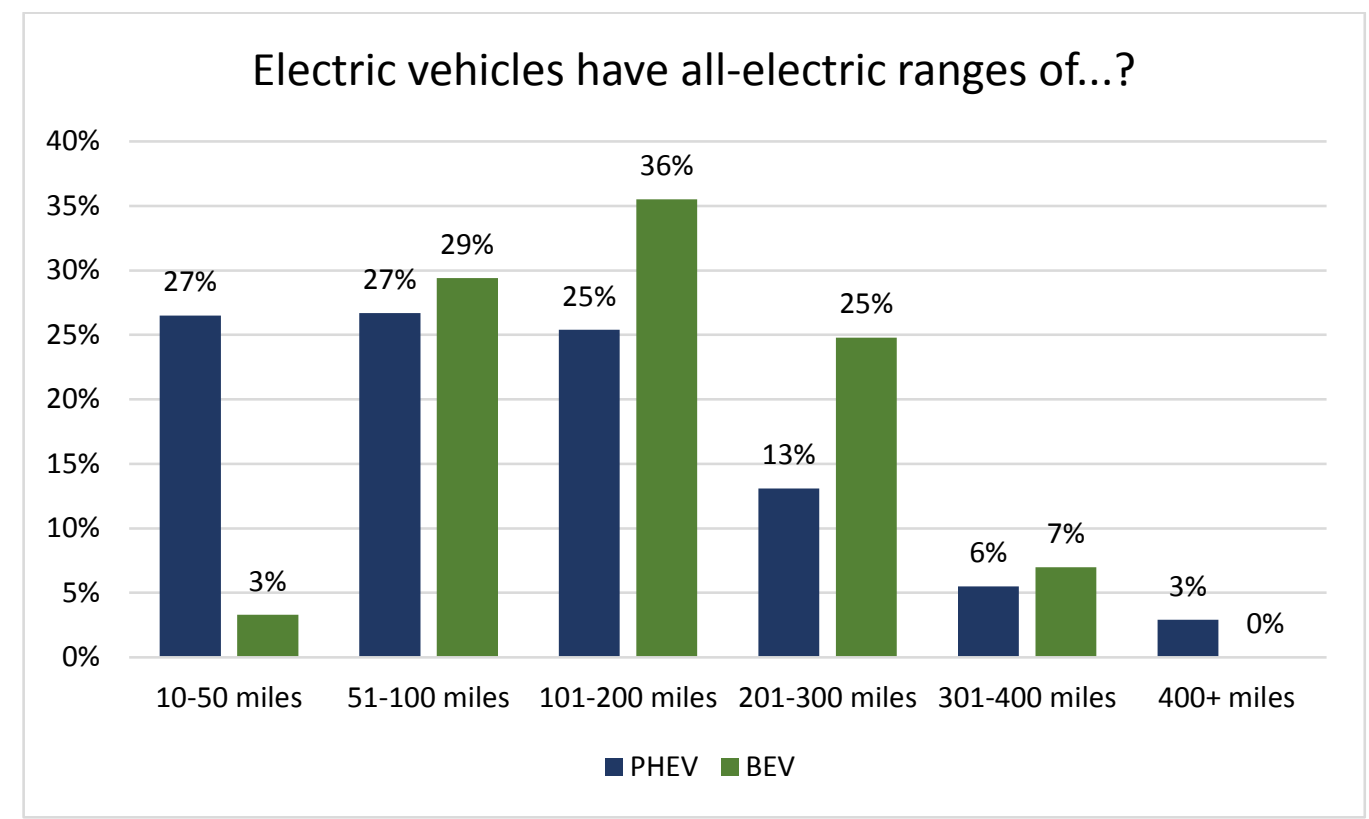

Figure 3: Non-EV Owners' Perceptions about EV All-Electric Ranges ( $n=765-766)$



Figure 4: Non-EV Owners' Perceptions about EV Charging Duration $(n=756-757)$

Respondents were also asked about their awareness of some of the financial benefits of purchasing EVs. Just about half of the respondents were aware that EV purchasers can receive up to a $\$ 7,500$ federal tax rebate. Respondents were much less aware that EV purchasers receive a 
$50 \%$ state tax credit up to a total of $\$ 750$ on EV vehicle charging equipment (28.6\%). Finally, hybrid and ICE vehicle owners were asked to what degree they agree with a range of statements about their knowledge of EVs (Figure 5). It appears that more than $75 \%$ of the respondents agree to some level that they are knowledgeable about EVs. The results also suggest a strong desire to learn more about EVs. Of the three statements the one with the highest rate of agreement was, "I am familiar enough with electric vehicles to make a decision about whether one is right for my household;" more than $80 \%$ of the respondents reported that they somewhat agree or agree that this was the case.

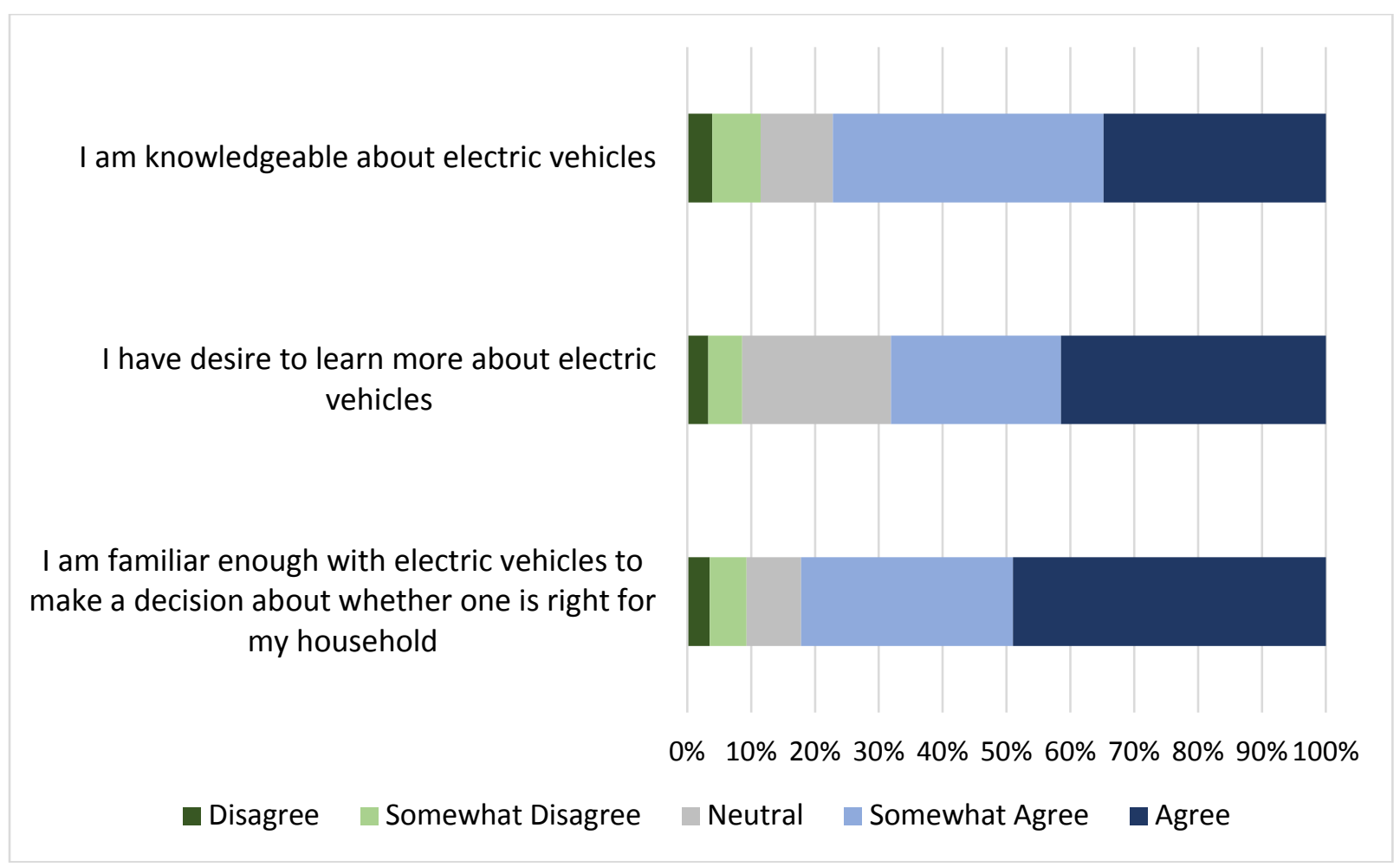

Figure 5: Non-EV Owners' Familiarity with EVs ( $n=777-778)$

Table 2 shows the different sources of information from which hybrid and ICE vehicle owners have received information about EVs. The most commonly selected sources were news stories/articles (59.4\%); friends, family, and colleagues (48.8\%); and manufacturers' websites (33.2\%). Each of these sources were rated as either moderately useful or very useful by over $90 \%$ of the respondents who selected them. Non-profit organizations and government agencies were among the least reported sources of information. However, these sources were rated highly for their usefulness; $100 \%$ of the respondents who selected non-profit rated the information as useful and $94.5 \%$ rated government agencies as useful. Approximately $15 \%$ of the sample selected that they have not received any information about electric vehicles. 
Table 2: Sources of EV Information

\begin{tabular}{lccc}
\hline & \multicolumn{3}{c}{ Percentages by Group } \\
\cline { 2 - 4 } Have you received info from...? & Total & ICE & Hybrid \\
\hline News stories/articles & 59.4 & 63.7 & 58.6 \\
Friends, family, colleagues & 48.8 & 47.6 & 49.0 \\
Manufacturers' websites & 33.2 & 49.2 & 30.2 \\
Magazines & 29.0 & 30.6 & 28.7 \\
TV/print advertisements & 28.8 & 29.8 & 28.5 \\
Car-related blogs/websites & 24.8 & 35.5 & 22.7 \\
Social media & 20.3 & 21.8 & 20.0 \\
Car salespeople & 14.9 & 30.6 & 11.9 \\
Online discussion forums & 12.1 & 16.9 & 11.1 \\
Government agencies & 8.0 & 14.5 & 6.7 \\
Non-profit organizations & 6.2 & 6.5 & 6.1 \\
Other & 5.9 & 15.3 & 4.1 \\
I have not received any information about & 14.5 & 10.5 & 15.3 \\
electric vehicles & 779 & 124 & 655 \\
\hline $\mathrm{n}$ & \multicolumn{3}{c}{} \\
\hline
\end{tabular}

\subsection{PERCEPTIONS}

A range of questions were utilized to assess hybrid and ICE vehicle owners' perceptions and attitudes towards EVs. Attitudinal responses to six statements regarding EVs are presented in Figure 6. The majority of respondents agreed that EVs are good for the environment (68.3\%) and that EVs are safe vehicles (53.1\%). When considering those who somewhat agree these proportions reached $90 \%$ and $80 \%$, respectively. The most commonly disagreed with statement was, "electric vehicles are convenient vehicles;" $24.5 \%$ of respondents somewhat disagreed or disagreed with this statement. Nearly half of the respondents reported that they were neutral about the statement that EVs are fun to drive. This can be expected as only a quarter of this group had driven an $\mathrm{EV}$ at the time of the survey. 


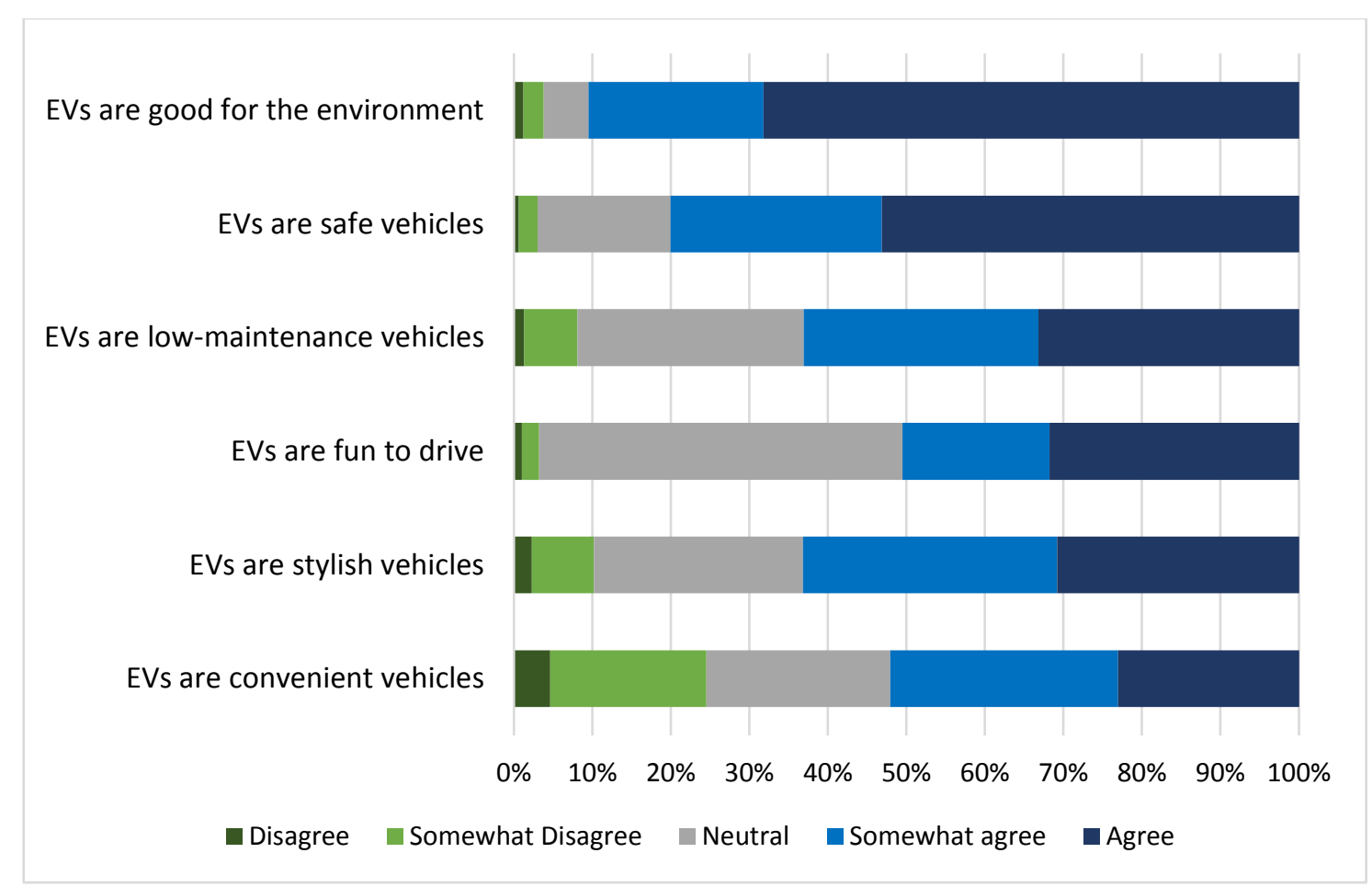

Figure 6: Non-EV Owners' Perceptions of EVs $(n=771-778)$

Responses to a series of five questions addressing perceptions of public charging infrastructure, EVs in comparison to other vehicles, and gasoline prices are presented in Table 3 . The results indicate that just over 50\% of hybrid and ICE vehicle owners believe that the public charging infrastructure is sufficient enough for them to feel comfortable driving an EV. Less than half of the respondents felt that EVs are better than conventional gas vehicles; however, $82.3 \%$ were in favor of EVs replacing gas vehicles over time. There appears to be a general consensus that EVs are better for the environment than hybrid vehicles. Most hybrid and ICE vehicle owners also felt that they believe the price of gas is going to increase over the course of the next five years. Some of these perceptions may influence an individual's decision to purchase an electric vehicle. For example, someone concerned with the lack of public charging infrastructure may be deterred from purchasing an EV. On the other hand, someone worried about the increase of gasoline costs might be influenced to transition to an electrically powered vehicle. This topic is covered in depth in the following section. 
Are there enough public charging stations available for you to feel comfortable driving an electric vehicle?

No

Yes

\begin{tabular}{|c|c|}
\hline Count & Percent \\
\hline 397 & 51.1 \\
\hline 214 & 27.5 \\
\hline 166 & 21.4 \\
\hline 372 & 47.9 \\
\hline 277 & 35.7 \\
\hline 127 & 16.4 \\
\hline 51 & 6.6 \\
\hline 637 & 82.3 \\
\hline 86 & 11.1 \\
\hline 579 & 75.1 \\
\hline 172 & 22.3 \\
\hline 20 & 2.6 \\
\hline 147 & 18.9 \\
\hline 558 & 71.8 \\
\hline 45 & 5.8 \\
\hline 27 & 3.5 \\
\hline
\end{tabular}

\subsection{LIKELIHOOD TO PURCHASE AN ELECTRIC VEHICLE}

There are many factors that may increase or diminish an individual's likelihood to purchase an $\mathrm{EV}$, such as awareness of the technology, cost savings, and range anxiety. This section explores intrinsic and extrinsic motivations and concerns of purchasing an electric vehicle. Specific factors that may increase a potential buyer's interest and the respondents' expectations for their next vehicle are also addressed.

Respondents were asked to select and then rank the top three reasons they might consider purchasing an EV. They were given 10 prescribed choices with the option to select "other" and explain their motivation. The proportion of the hybrid and ICE vehicle owners who selected each option and the proportion who ranked it as the top motivator are presented in Table 4 . The desire 
to reduce environmental impact caused by driving was by far the most selected choice; $76.5 \%$ of all hybrid and ICE owners selected this choice and 53.6\% rated it as their top motivation for considering an EV. Other important factors included saving money on the cost of fuel and reducing the amount of oil imported into the USA. The least-reported motivations were "my workplace offers incentives" and "the lease deals for electric vehicles are too good to pass up;" these options were selected by a mere $1.2 \%$ and $3.1 \%$ of this sub-sample, respectively.

Table 4 also shows proportions disaggregated by car type (hybrid and ICE) and land designation (urban and rural). A few significant differences between groups appear, most notably hybrid owners and urbanites were significantly more likely to select and prioritize reducing their driving's impact on the environment. They were also more likely to choose reducing the amount of oil into the USA as an important motivator. Both ICE vehicle owners and rural respondents valued their interest in new technology over reducing oil imports. ICE vehicle owners were also more likely to select and prioritize having access to public infrastructure as a motivator. This coincides with the finding that they were much more likely to state that there are enough public charging stations available to feel comfortable driving an EV when compared to hybrid owners (40\% and 25\%, respectively). Lastly, it is important to note that while "my workplace offers incentives" was the least-chosen option; absolutely no rural respondents selected this as an important motivator. 
Table 4: Selected and Priortized Reasons Non-EV Owners Might Consider Purchasing an EV

\begin{tabular}{|c|c|c|c|c|c|c|c|c|c|c|}
\hline \multirow[b]{4}{*}{$\begin{array}{l}\text { I want to reduce my driving's } \\
\text { effect on the environment }\end{array}$} & \multicolumn{10}{|c|}{ Percentages by Group } \\
\hline & \multicolumn{2}{|c|}{ All } & \multicolumn{2}{|c|}{ ICE } & \multicolumn{2}{|c|}{ Hybrid } & \multicolumn{2}{|c|}{ Urban } & \multicolumn{2}{|c|}{ Rural } \\
\hline & Selected & $\begin{array}{l}\text { Ranked } \\
1 \text { st }\end{array}$ & Selected & \begin{tabular}{c|c} 
Ranked & \\
1 st
\end{tabular} & Selected & $\begin{array}{c}\text { Ranked } \\
1 \text { st }\end{array}$ & Selected & $\begin{array}{l}\text { Ranked } \\
1 \text { st }\end{array}$ & Selected & $\begin{array}{c}\text { Ranked } \\
1 \text { st }\end{array}$ \\
\hline & 76.5 & 52.6 & 64.8 & 36.4 & 78.8 & 55.6 & 78.8 & 55.1 & 64.5 & 40.0 \\
\hline $\begin{array}{l}\text { I want to save money on the cost } \\
\text { of fuel }\end{array}$ & 50.8 & 16.5 & 45.9 & 20.3 & 51.8 & 15.8 & 50.8 & 15.8 & 50.8 & 20.8 \\
\hline $\begin{array}{l}\text { I want to reduce the amount of } \\
\text { oil imported into the USA }\end{array}$ & 38.2 & 6.9 & 28.7 & 8.5 & 40.0 & 6.5 & 40.0 & 6.3 & 29.0 & 9.2 \\
\hline $\begin{array}{l}\text { I am interested in the new } \\
\text { technology }\end{array}$ & 29.2 & 5.1 & 36.9 & 6.8 & 27.8 & 4.8 & 28.6 & 5 & 33.1 & 5.8 \\
\hline $\begin{array}{l}\text { The federal tax incentives are } \\
\text { financially appealing }\end{array}$ & 24.4 & 4.2 & 22.1 & 5.1 & 24.8 & 4.0 & 23.6 & 3.7 & 28.2 & 5.8 \\
\hline $\begin{array}{l}\text { The price of electric vehicles } \\
\text { (after tax credits) makes them a } \\
\text { good value }\end{array}$ & 18.8 & 4.7 & 17.2 & 2.5 & 19.1 & 5.1 & 18.3 & 4.3 & 21.0 & 6.7 \\
\hline $\begin{array}{l}\text { I like the statement that owning } \\
\text { an electric vehicle makes }\end{array}$ & 17.2 & 1.3 & 13.9 & 0.0 & 17.8 & 1.6 & 16.9 & 1.3 & 18.5 & 1.7 \\
\hline $\begin{array}{l}\text { I have access to public charging } \\
\text { infrastructure at the places I go }\end{array}$ & 9.4 & 3.1 & 15.6 & 7.6 & 8.2 & 2.2 & 9.2 & 3.1 & 10.5 & 3.3 \\
\hline Other & 7.7 & 3.9 & 13.9 & 10.2 & 6.5 & 2.7 & 7.2 & 3.7 & 10.5 & 5.0 \\
\hline $\begin{array}{l}\text { The lease deals for electric } \\
\text { vehicles are too good to pass up }\end{array}$ & 3.1 & 0.9 & 9.8 & 1.7 & 1.9 & 0.8 & 3.0 & 1.0 & 4.0 & 0.8 \\
\hline My workplace offers incentives & 1.2 & 0.3 & 3.3 & 0.8 & 0.8 & 0.2 & 1.3 & 0.3 & 0.0 & 0.0 \\
\hline $\mathrm{n}$ & 767 & 744 & 122 & 118 & 645 & 626 & 640 & 621 & 124 & 120 \\
\hline
\end{tabular}

Note: Bold indicates significant differences between groups based on a chi-squared test ( $p<.05)$; values being compared are color coded row-wise. 
Hybrid and ICE vehicle owners' concerns about purchasing or leasing an EV were addressed in a similar way; they were to choose and rank their top three concerns from 12 prescribed options with the additional option to select "other" and explain; results are presented in Table 5. The most frequently selected concerns were, "electric vehicles are not convenient for long trips," "I feel anxious about getting stranded due to running out of electricity," and "there are not enough public charging stations.” The concern with the cost of EVs was not among the top three; however, it was more likely to be ranked as the primary concern than all but one option. The low resale value of EVs and the concern over the appeal of available EV models were among the least-cited concerns.

When these results were disaggregated by car type and land designation, differences between groups were highlighted (see Table 5). Again, we see that ICE vehicle owners are significantly less concerned with the availability of public charging infrastructure. They were also significantly less likely to rank their knowledge about EVs, the difficulties of installing a home charger, and the low-resale values as important concerns. On the other hand, they were significantly more likely to prioritize the concern about the convenience of EVs for long trips. Concerns did not appear to vary much between urban and rural respondents. The only significant differences were that rural residents were more likely to prioritize concerns about replacing the battery and rank the appeal of available models as an important concern. 


\begin{tabular}{|c|c|c|c|c|c|c|c|c|c|c|}
\hline \multirow[b]{5}{*}{$\begin{array}{l}\text { Electric vehicles are not convenient } \\
\text { for long trips }\end{array}$} & \multicolumn{10}{|c|}{ Percentages by Group } \\
\hline & \multicolumn{2}{|c|}{ ALL } & \multicolumn{2}{|c|}{ ICE } & \multicolumn{2}{|c|}{ Hybrid } & \multicolumn{2}{|c|}{ Urban } & \multicolumn{2}{|c|}{ Rural } \\
\hline & & Ranked & & Ranked & & Ranked & & Ranked & & Ranked \\
\hline & Selected & 1st & Selected & 1st & Selected & 1st & Selected & 1 st & Selected & $1 \mathrm{st}$ \\
\hline & 66.8 & 29.2 & 68.9 & 37.4 & 66.5 & 27.7 & 67.7 & 30.0 & 62.4 & 24.4 \\
\hline $\begin{array}{l}\text { I feel anxious about getting stranded } \\
\text { due to running out of electricity }\end{array}$ & 40.4 & 13.5 & 36.1 & 15.7 & 41.3 & 13.1 & 40.4 & 14.3 & 39.2 & 9.2 \\
\hline $\begin{array}{l}\text { There are not enough public charging } \\
\text { stations }\end{array}$ & 37.5 & 9.7 & 29.5 & 7.8 & 38.9 & 10.0 & 37.0 & 9.0 & 40.0 & 13.4 \\
\hline Electric vehicles are too expensive & 29.0 & 15.3 & 23 & 10.4 & 30.1 & 16.2 & 27.9 & 15.0 & 35.2 & 17.6 \\
\hline Recharging the battery takes too long & 23.0 & 3.0 & 26.2 & 3.5 & 22.4 & 2.9 & 24.0 & 2.6 & 17.6 & 5.0 \\
\hline $\begin{array}{l}\text { I have concerns about having to } \\
\text { replace the battery }\end{array}$ & 17.8 & 4.6 & 20.5 & 6.1 & 17.3 & 4.3 & 16.8 & 3.9 & 23.2 & 8.4 \\
\hline $\begin{array}{l}\text { Today's electric vehicle technology } \\
\text { will be outdated soon }\end{array}$ & 16.1 & 3.2 & 18.9 & 5.2 & 15.6 & 2.9 & 16.1 & 3.1 & 16.0 & 3.4 \\
\hline $\begin{array}{l}\text { I do not know enough about electric } \\
\text { vehicles }\end{array}$ & 15.6 & 8.2 & 5.7 & 1.7 & 17.5 & 9.4 & 15.8 & 8.2 & 15.2 & 8.4 \\
\hline $\begin{array}{l}\text { Installing a home charger would be } \\
\text { difficult }\end{array}$ & 11.6 & 4.4 & 5.7 & 0.9 & 12.7 & 5.1 & 12.2 & 4.7 & 8.8 & 3.4 \\
\hline Other & 7.8 & 4.6 & 13.1 & 8.7 & 6.8 & 3.8 & 7.8 & 4.8 & 8.0 & 3.4 \\
\hline $\begin{array}{l}\text { My workplace does not have charging } \\
\text { stations }\end{array}$ & 5.9 & 1.3 & 5.7 & 0.9 & 5.9 & 1.4 & 6.2 & 1.4 & 4.0 & 0.8 \\
\hline $\begin{array}{l}\text { The electric vehicle models that are } \\
\text { available do not appeal to me }\end{array}$ & 5.7 & 2.0 & 5.7 & 0.0 & 5.7 & 2.4 & 5.0 & 2.1 & 9.6 & 1.7 \\
\hline $\begin{array}{l}\text { Electric vehicles have low resale } \\
\text { value }\end{array}$ & 3.8 & 0.7 & 12.3 & 0.9 & 2.2 & 0.6 & 3.7 & 0.8 & 3.2 & 0.0 \\
\hline $\mathrm{n}$ & 769 & 743 & 122 & 115 & 647 & 628 & 641 & 621 & 125 & 119 \\
\hline
\end{tabular}

Note: Bold indicates significant differences between groups based on a chi-squared test ( $p<.05)$; values being compared are color coded row-wise. 
Respondents were also asked whether certain changes would increase their interests in purchasing or leasing an EV. Figure 7 shows the proportion of respondents who selected each statement as something that would increase their interest in purchasing or leasing an EV; respondents were allowed to select up to three options. Battery warranties, assistance with installing home charging equipment, and a shift from a tax credit to a point-of-sale rebate were the top three selected choices. The availability of more used EVs and a battery leasing program were among the least commonly selected. The proportions of ICE and hybrid vehicle owners differ within each of the changes. Most notably, hybrid vehicle owners were much more likely to select assistance with installing a home charger as a change that would increase their interest in purchasing an EV. ICE vehicle owners were more likely to report that an increase in gas prices above five dollars per gallon would increase their interest. Results from a more specific set of questions indicate that the majority of respondents would be more interested in purchasing or leasing an EV if the battery range increased to 300 or more miles (67.2\%); if there was a \$2,500 tax rebate for BEVs and a $\$ 1,500$ tax rebate for PHEVs (59.2\%); and if the time it takes to charge at public charging stations is reduced to 30 minutes or less (69.1\%).

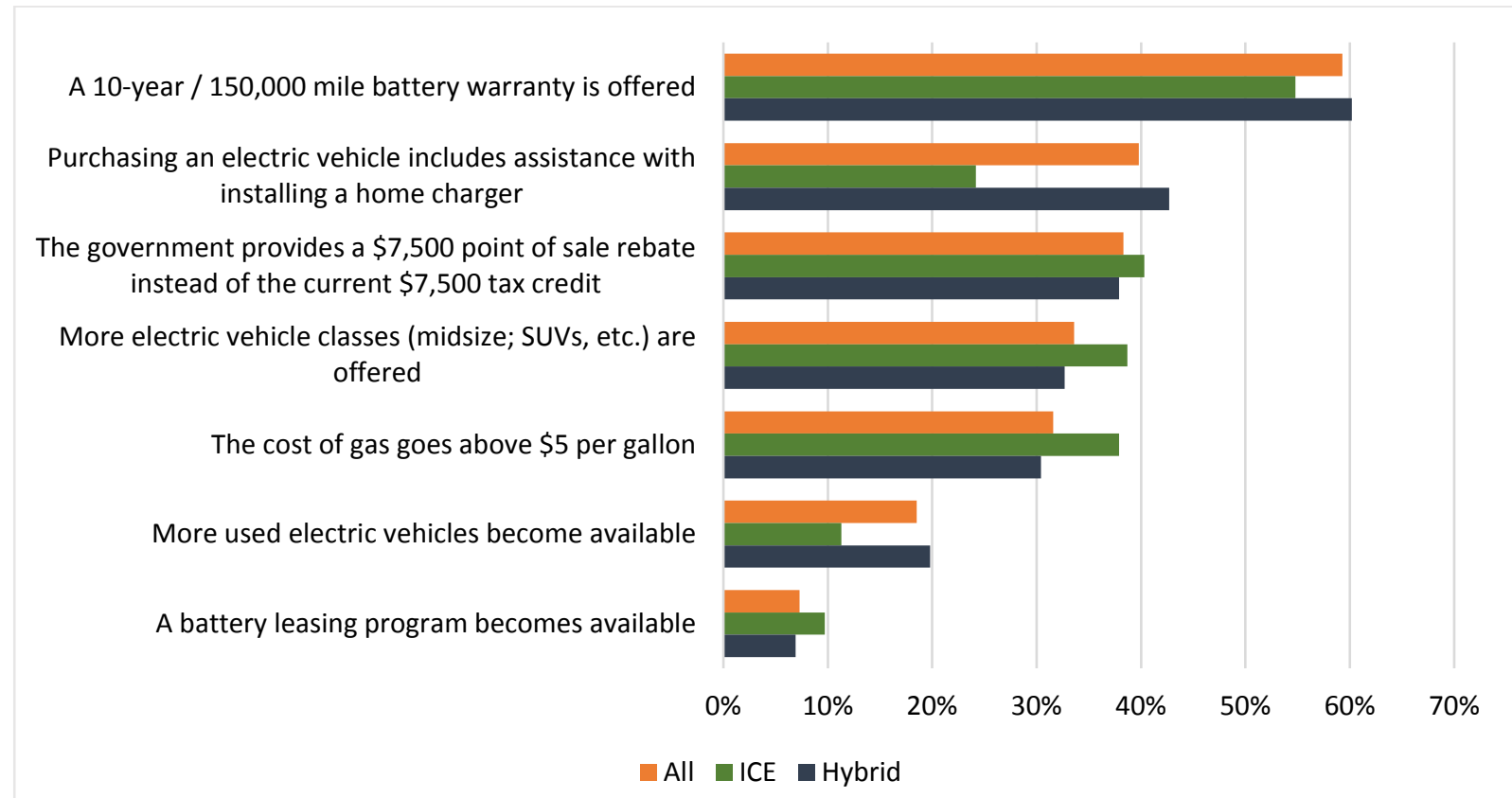

Figure 7: Factors that Could Increase Interests in Purchasing an EV (n=779)

Respondents were also asked how likely it is that their next vehicle will be a PHEV, BEV, hybrid vehicle, and a brand-new vehicle (Figure 8). In regards to car type, respondents commonly reported that it is most likely that their new car would be a hybrid vehicle (36.8\%), $11.2 \%$ said it is likely their next car would be a PHEV, and $15.4 \%$ reported it is likely their next car will be a BEV. Respondents also most commonly reported that it is likely that the next vehicle they buy will be brand new. 


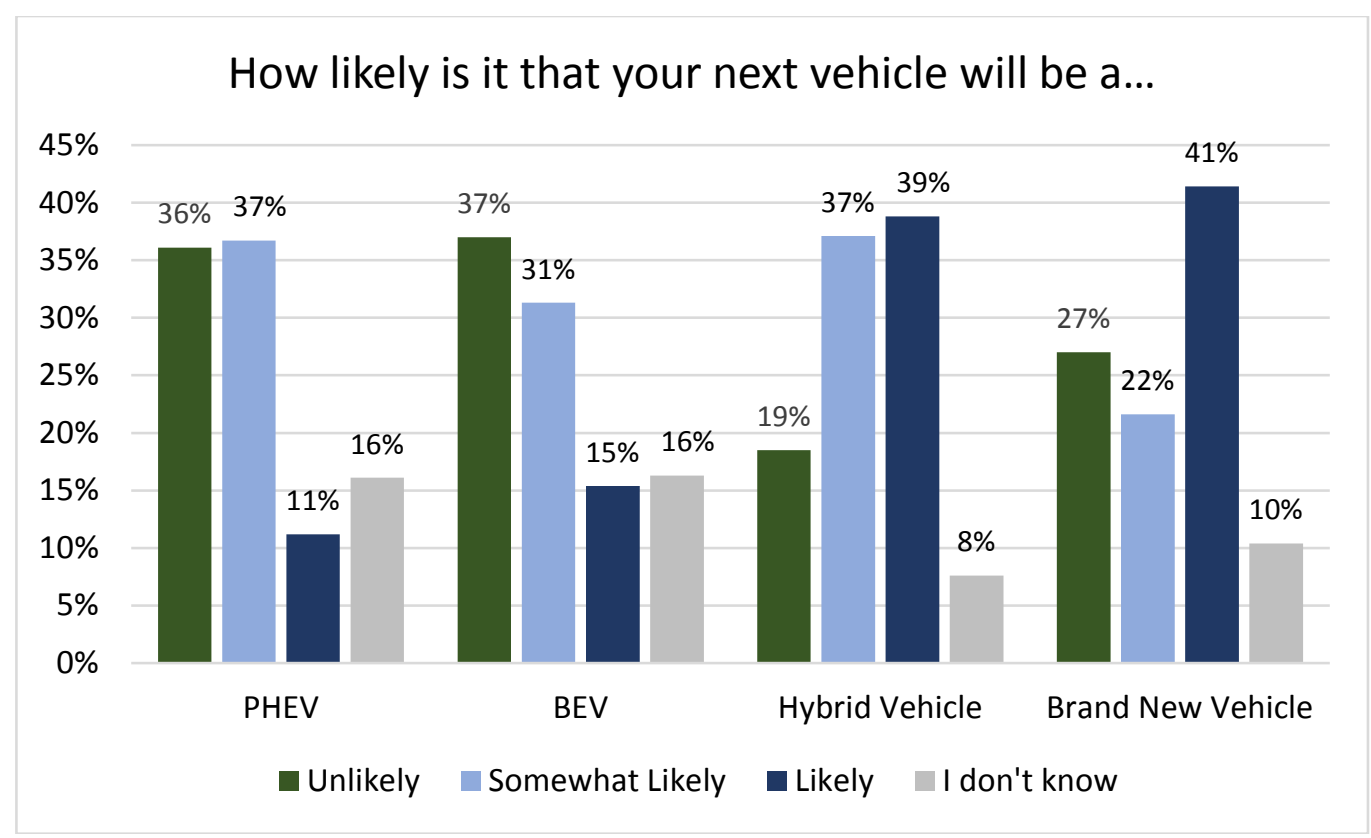

Figure 8: Liklihood to Purchase Fuel-Efficient Vehicles ( $n=760-761)$ 


\subsection{ELECTRIC VEHICLE OWNERS}

This section explores the survey responses of EV owners. These respondents owned or leased either a BEV or a PHEV. This section consists of three parts. First, the demographic characteristics of EV respondents are presented. Second, various aspects of travel behavior and EV charging are explored in detail. Finally, EV respondents' motivations for purchasing an EV and their concerns about EVs are assessed. Both pre-purchase and post-purchase concerns are considered. Results are disaggregated by EV type (PHEV and BEV) and land designation (urban and rural) to highlight differences and similarities across populations. Comparing responses by EV type can also provide insight into the benefits and limitations of the different types of EVs.

\subsection{DEMOGRAPHICS}

Table 6: Demographics of EV Owners

\begin{tabular}{|c|c|c|c|c|}
\hline & \multicolumn{4}{|c|}{ Percentages by Group } \\
\hline & All Respondents & All EV & $\mathrm{BEV}$ & PHEV \\
\hline \multirow[t]{2}{*}{ Own or lease a vehicle } & $\mathrm{n}=4069$ & $\mathrm{n}=3290$ & $\mathrm{n}=2183$ & $\mathrm{n}=1086$ \\
\hline & 100.0 & 80.9 & 53.6 & 26.7 \\
\hline Race & $\mathrm{n}=3925$ & $n=3167$ & $\mathrm{n}=2100$ & $n=1046$ \\
\hline American Indian or Alaska Native & 0.6 & 0.6 & 0.7 & 0.6 \\
\hline Asian & 4.0 & 4.3 & 4.6 & 3.6 \\
\hline Black or African American & 0.5 & 0.5 & 0.5 & 0.5 \\
\hline Hispanic or Latino/a & 1.6 & 1.6 & 1.9 & 1.6 \\
\hline White or Caucasian & 89.1 & 88.4 & 87.6 & 88.5 \\
\hline Other & 4.3 & 4.5 & 4.7 & 4.5 \\
\hline Age & $\mathrm{n}=3906$ & $n=3150$ & $\mathrm{n}=2087$ & $n=1043$ \\
\hline $18-24$ & 0.7 & 0.4 & 0.4 & 0.5 \\
\hline $25-34$ & 7.3 & 6.7 & 6.6 & 6.9 \\
\hline $35-44$ & 18.4 & 19.4 & 21.4 & 15.5 \\
\hline $45-54$ & 22.6 & 23.7 & 26.2 & 19.1 \\
\hline $55-64$ & 25.3 & 25.1 & 24.6 & 25.8 \\
\hline $65+$ & 25.8 & 24.7 & 20.9 & 32.2 \\
\hline Gender & $\mathrm{n}=3935$ & $n=3173$ & $\mathrm{n}=2098$ & $n=1054$ \\
\hline Male & 65.3 & 67.3 & 68.2 & 65.9 \\
\hline Female & 34.2 & 32.2 & 31.3 & 33.7 \\
\hline Other & 0.5 & 0.5 & 0.6 & 0.4 \\
\hline Education & $\mathrm{n}=3955$ & $n=3192$ & $\mathrm{n}=2117$ & $n=1054$ \\
\hline High school or less & 1.8 & 1.8 & 1.3 & 2.8 \\
\hline Some college, no degree & 13.5 & 13.6 & 12.3 & 15.7 \\
\hline Associate's degree & 5.8 & 6.0 & 5.2 & 7.8 \\
\hline Bachelor's degree & 34.1 & 33.8 & 35.1 & 31.4 \\
\hline Post-graduate degree & 43.8 & 43.7 & 45.1 & 41.3 \\
\hline Prefer not to answer & 0.9 & 1.0 & 1.0 & 1.0 \\
\hline
\end{tabular}




\begin{tabular}{|c|c|c|c|c|}
\hline & \multicolumn{4}{|c|}{ Percentages by Group } \\
\hline & All Respondents & All EV & $\mathrm{BEV}$ & PHEV \\
\hline Currently employed & $n=3955$ & $n=3190$ & $n=2115$ & $\mathrm{n}=1054$ \\
\hline Yes & 70.6 & 72.5 & 75.6 & 66.4 \\
\hline Income & $n=3725$ & $n=3011$ & $n=1902$ & $n=931$ \\
\hline Less than $\$ 15,000$ & 0.7 & 0.7 & 0.6 & 0.7 \\
\hline$\$ 15,000-\$ 24,999$ & 1.4 & 1.4 & 1.4 & 1.3 \\
\hline$\$ 25,000-\$ 34,999$ & 2.6 & 2.1 & 2.2 & 2 \\
\hline$\$ 35,000-\$ 49,999$ & 5.7 & 4.8 & 4.5 & 5.2 \\
\hline$\$ 50,000-\$ 74,999$ & 13.4 & 12.6 & 11.7 & 14.4 \\
\hline$\$ 75,000$ - \$99,999 & 15.8 & 15.3 & 14.4 & 17.3 \\
\hline$\$ 100,000$ - \$149,999 & 27.3 & 27.8 & 27.8 & 27.7 \\
\hline$\$ 150,000+$ & 33.0 & 35.3 & 37.5 & 31.4 \\
\hline Household Tenure & $n=3946$ & $\mathrm{n}=3184$ & $n=2113$ & $\mathrm{n}=1050$ \\
\hline Own & 90.0 & 91.3 & 92.1 & 90.0 \\
\hline Political party & $n=3869$ & $\mathrm{n}=3113$ & $\mathrm{n}=2060$ & $n=1032$ \\
\hline Democrat & 56.3 & 54.9 & 55.7 & 53.5 \\
\hline Independent & 11.8 & 12.1 & 11.9 & 12.6 \\
\hline Working families & 0.9 & 0.9 & 1.1 & 0.3 \\
\hline Non-affiliated & 14.2 & 14.8 & 15.1 & 14.1 \\
\hline Republican & 9.7 & 10.1 & 8.7 & 12.6 \\
\hline Libertarian & 1.8 & 1.9 & 1.9 & 1.9 \\
\hline Pacific Green & 2.1 & 2.2 & 2.1 & 2.2 \\
\hline Other & 3.2 & 3.2 & 3.4 & 2.7 \\
\hline
\end{tabular}

Table 6 displays selected demographic characteristics. EV respondents, like the overall respondent sample, are predominately white (88.4\%), highly educated (77.5\%), males (67.3\%) and living in households with an annual income greater than $\$ 100,000$ (63.1\%). EV owners make up $80.9 \%$ of the total sample (53.6\% owned or leased a BEV and 26.7\% a PHEV). Most EV respondents were homeowners (91.3\%), currently employed (72.5\%), and politically identified as a Democrat (54.9\%). This group has a higher proportion of adults between the ages of 35-54 and are more likely to have a household income greater than $\$ 100,000$, when compared to the average.

EV respondents reported additional characteristics that are not listed in the table. Of those who were currently employed, 89.9\% worked at a location outside of their home. Most EV owners lived in single-family detached homes (89.6\%); this proportion was greater for BEV owners (90.2\%) than it was PHEV owners (88.8\%). More than 95\% of the respondents in each group owned a smartphone. Most EV respondents lived in areas classified as urban (83.3\%); however, PHEV owners were far more likely to live in rural areas (23.1\%) than BEV owners (13.6\%).

Of the EV sample, $66.8 \%$ are BEV owners and 33.2\% are PHEV owners $(n=3,271)$. Table 7 shows the proportion of respondents who own or lease their vehicle and bought their vehicle new or used. The majority of respondents own their EV and bought them new; these proportions were greater for PHEV respondents than they were BEV respondents. Among BEV respondents, Nissan was by far the most popularly owned brand; of the 2,180 reported BEVs, 972 or $44.6 \%$ 
were made by Nissan. Combined Chevrolet and Tesla accounted for an additional 27.5\%. Approximately 53\% of the BEVs were made in 2015 or later, 47\% were $2010-2014$ models, and less than $1 \%$ were made before 2010. For PHEV respondents the most popular brand vehicle was Chevrolet, accounting for 472 of the 1,083 reported PHEVs, or 43.6\%. Combined, Ford and Toyota accounted for an additional $44.8 \%$. Nearly half of the PHEVs were produced in 2015 or later, 50.7\% between 2010 and 2014, and less than 1\% prior to 2010 .

Table 7: Purchasing Characteristics

\begin{tabular}{cccc}
\hline & \multicolumn{3}{c}{ Percentages by Group } \\
\cline { 2 - 4 } Do you lease or own your EV? & All EV & BEV & PHEV \\
\cline { 2 - 4 } Lease & $\mathrm{n}=3271$ & $\mathrm{n}=2173$ & $\mathrm{n}=1078$ \\
Own & 33.2 & 37.1 & 25.6 \\
Did you buy your EV new or used? & 66.8 & 62.9 & 74.4 \\
New & $\mathrm{n}=3279$ & $\mathrm{n}=2178$ & $\mathrm{n}=1082$ \\
Used & 74.5 & 72.4 & 79.2 \\
\hline
\end{tabular}

\subsection{EV USE AND CHARGING BEHAVIOR}

Respondents were asked to report some information on their daily driving habits. The average daily vehicle miles traveled (VMT) per person was 32 miles. On average, rural residents drove a significantly greater distance per day (41 miles) than did urban residents (31 miles) ( $\mathrm{p}=.000)$. The average daily commute (one direction) was 8.6 miles for all respondents. Again, rural residents had a significantly longer average commute (11 miles) than urban residents (8 miles) ( $\mathrm{p}=.000)$. "Low," "Average," and "High" categories of daily VMT were created based off of Portland Metro's average daily VMT per person, which is 18.7 miles (Low $\leq 15$ miles; Average = 16-21 miles; High $\geq 22$ miles) (Metro, 2010). Figure 9 depicts the proportion of respondents who fall under each of these categories. Urban residents were more likely to fall under the low and average daily VMT categories, while rural residents were far more likely to fall under the high daily VMT category. Furthermore, rural residents were significantly less likely to drive $100 \%$ of those miles in an EV (19 \%) than were urban residents (29 \%). Nearly 30\% of rural respondents reported that none of the miles they drive in a typical day are made in an EV; they were more likely to report driving most of those miles in a hybrid or gas vehicle. Correspondingly, respondents who had high daily VMT were less likely than those with low or average daily VMT to drive $100 \%$ of their daily miles in an EV. 


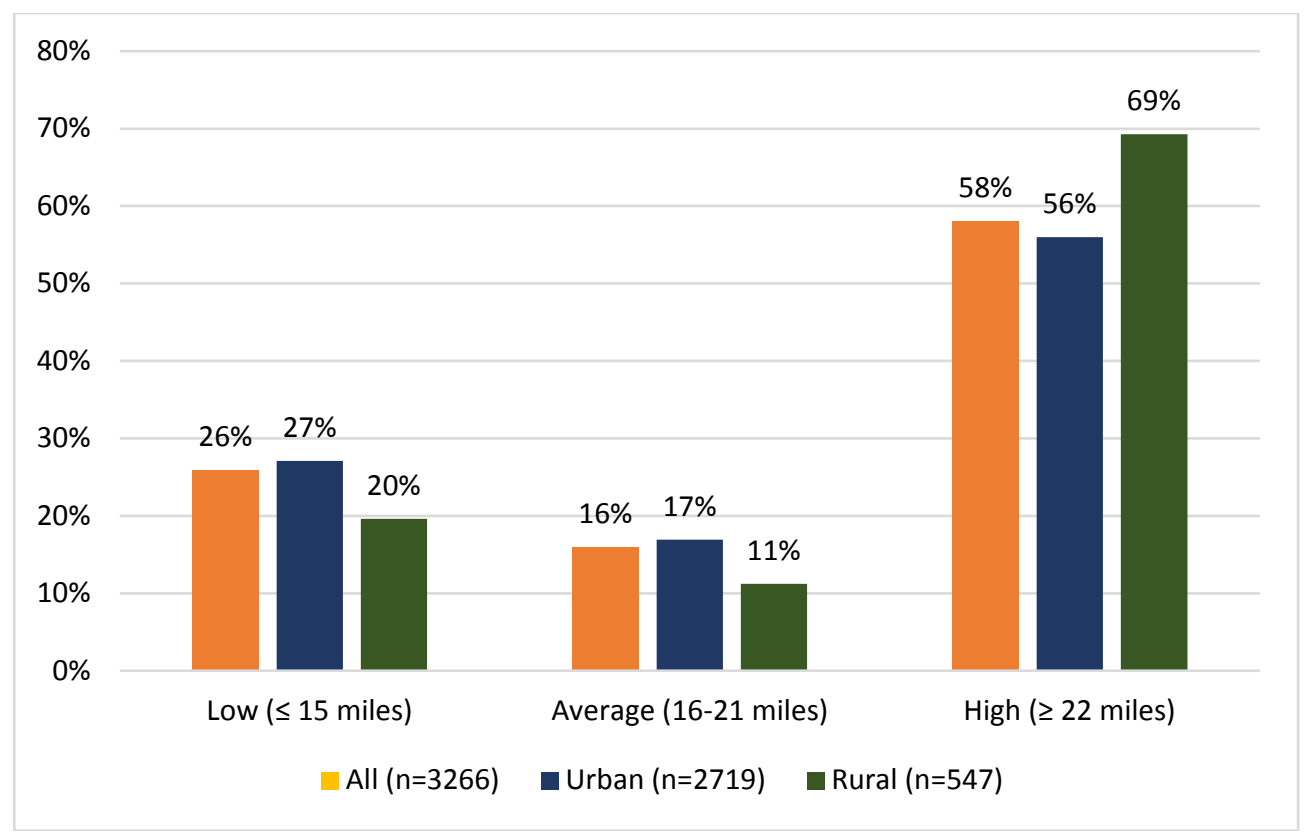

Figure 9: Miles Driven in a Typical Day by Urban/Rural Land Designation

EV owners were asked to respond to a variety of questions about their charging habits, access to charging, and their satisfaction with EV public charging equipment. Figure 10 shows how often respondents charge their EVs. The majority of respondents charge their EVs every day or multiple times a day. It appears that BEV owners tend to charge their vehicle less frequently than PHEV owners; higher proportions of BEV owners charge their vehicles 1-6 times per week and lower proportions of BEV owners charge their vehicle once a day or more.



Figure 10: Charging Frequency 
Figure 11 shows where respondents tend to charge their cars. When disaggregated by car type and land designation, there was little discrepancy between groups; the only notable difference was that PHEV owners were more likely to do the majority of their charging at home and less likely to charge at public charging stations.

Charging at Home: Just under two-thirds of the respondents reported that $100 \%$ of their weekly charging takes place at home; $46 \%$ of all EV owners have a Level 2 charger installed at their home (this proportion is higher for BEV owners at 53\%). Respondents most commonly reported that they charge mostly overnight (68.0\%). PHEV owners and rural residents were more likely to report charging overnight and during the day than their counterparts.

Charging at Work: While $40.7 \%$ of the respondents reported that they had the option to charge at work, the vast majority reported that none of their weekly charging takes place at work. Of those who had the option to charge at work, $43.7 \%$ were required to pay for charging. Rural residents (25.9\%) were far less likely to have to pay for charging at work than urban residents (46.3\%).

Charging in Public: Finally, 26.1\% of respondents reported that at least some charging happens at public charging stations. Despite this finding, only $10.6 \%$ of respondents reported that they use public charging at least one time per week, while most (72.9\%) reported using public charging a few times a year or never. BEV owners and rural residents were more likely to utilize public charging once a week or more. These groups were also more likely to spend 30 minutes charging at these stations, while their counterparts, PHEV owners and urban residents, were more likely to spend an hour to three hours charging at these stations. Mobile apps were the most commonly reported way of finding public charging infrastructure (43.7\%); however, a considerable proportion of respondents reported already knowing where the stations were located (31.8\%). PHEV owners were significantly less likely to utilize mobile apps (29.7\%) and in-car telematics (3.6\%) than BEV owners (50.9\% and 24.5\%, respectively). Rural residents were also less likely to use mobile apps than urban residents; PlugShare was the most commonly utilized app for all groups. Wayfinding signs were used to find public charging stations by less than 5\% of all respondents; this figure was lower than 3\% for rural residents. 


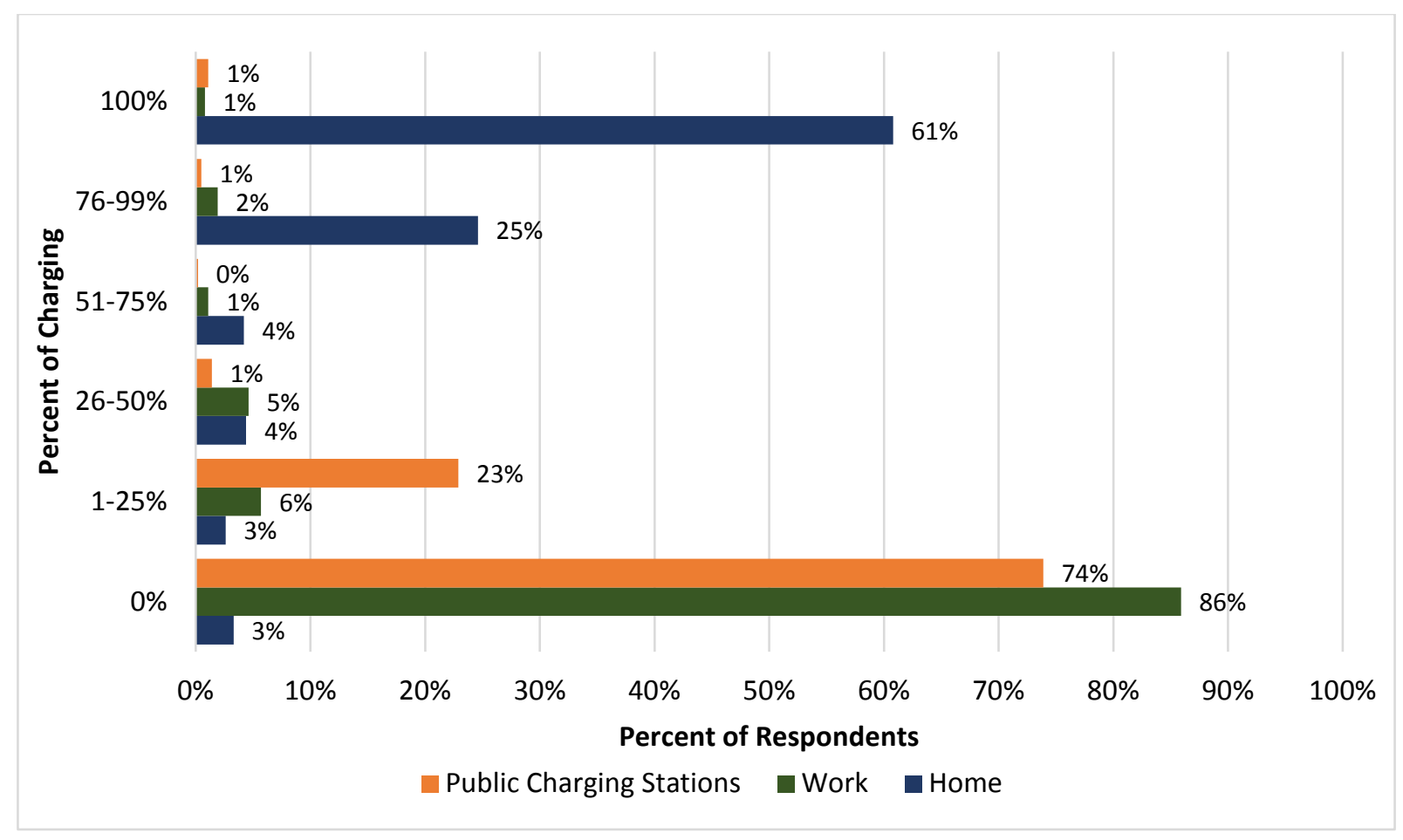

Figure 11: Percent of Charging that Takes Place at Each Location $(n=3,278-88)$

Respondents were asked about their satisfaction with the quantity of Level 2 chargers, the quantity of DC fast chargers, and the quality of the overall public charging experience. The proportion of respondents who reported being somewhat satisfied or satisfied with these conditions are depicted in Figure 12. The results indicate that respondents were most likely to be satisfied with the quantity of Level 2 chargers (44.8\%). BEV owners were more likely to be satisfied with each circumstance and were two times more likely to be satisfied with the quantity of DC fast chargers when compared to PHEV owners. There were no notable differences in satisfaction rates between urban and rural residents. 




Figure 12: Satisfaction with Public Charging Infrastructure

Respondents were asked to rank a set of public charging improvements from 1 to 5 (1 being the most important). Results are presented in Figure 13. "More public fast chargers" was ranked first and second, more than any of the other improvements. "More public charging along freeways for long-distance trips" was more equally distributed than the others and was ranked first, second or third by over 70\% of the respondents. "More public chargers at the places I visit regularly" was ranked third by the greatest proportion of respondents, yet it was also the least likely to be ranked first. "Cheaper charging” was ranked fourth by a significantly greater proportion of respondents when compared to other improvements, and it was also most commonly ranked as the least important infrastructural improvement. Disaggregating these results by car type revealed considerable differences in the infrastructural improvements prioritized by BEV owners and PHEV owners. BEV owners were more likely to prioritize more public chargers along freeways and more public fast chargers. On the other hand, PHEV owners were far more likely to prioritize "more public chargers at the places I visit regularly" and "cheaper charging." 


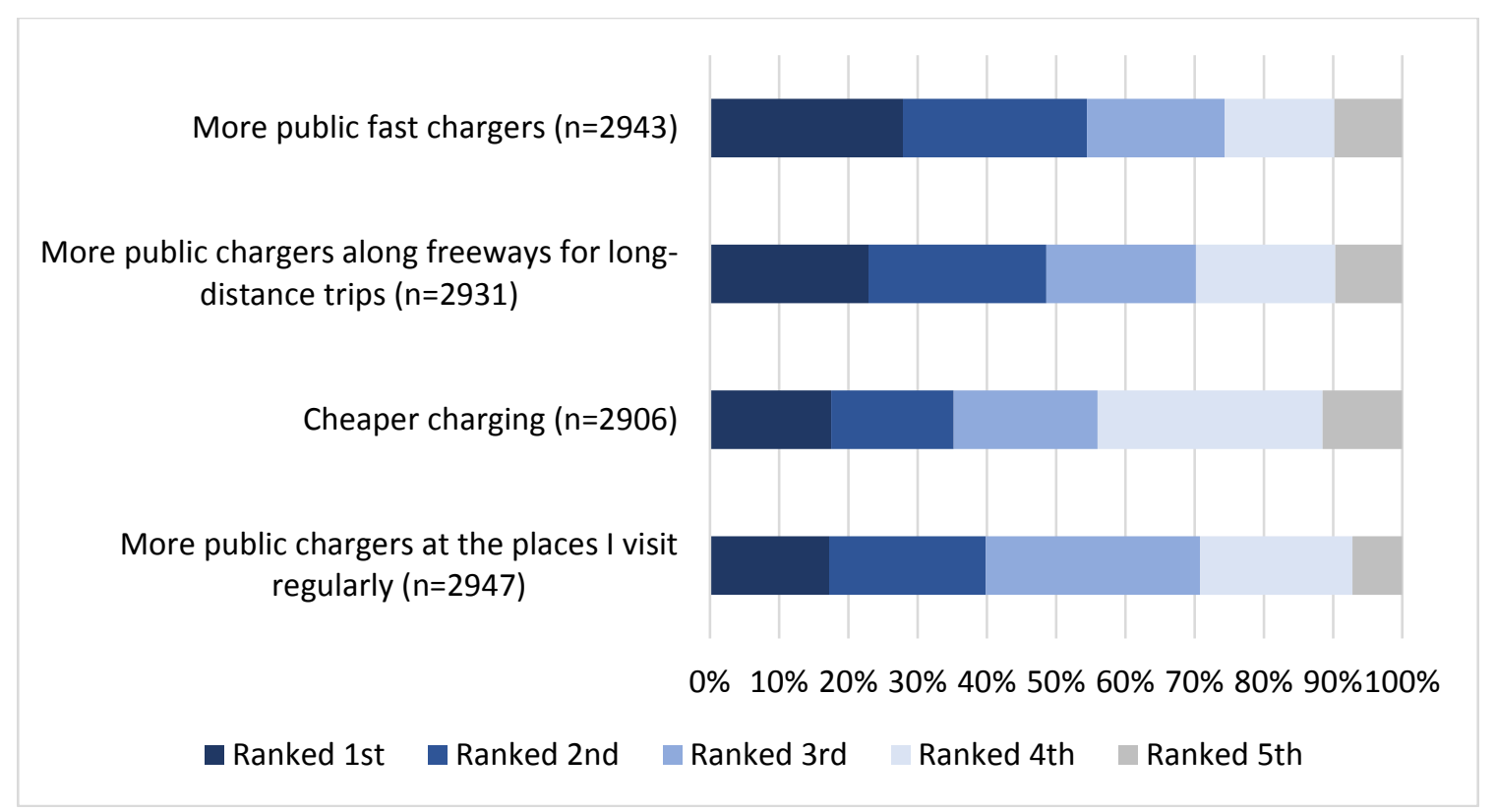

Figure 13: Importantance of Public Charging Infrastrcuture Improvements

\subsection{MOTIVATIONS AND CONCERNS}

Respondents who currently own or lease an EV were asked to select and rank the top three factors that contributed to their decision to purchase or lease an EV; they were provided nine prescribed factors and the option to select "other" and explain their reasoning. Table 8 shows the proportion of respondents who selected each factor as well as the proportion who ranked it as their primary motivation. The majority of respondents reported that reducing their driving's impact on the environment was an important reason for purchasing or leasing an EV (75.6\%); nearly half ranked this as the primary motivation. Wanting to save on the cost of fuel and interest in the new technology were also important motivators. "I had access to public charging infrastructure at the places I go" and "My workplace offered incentives" were the least frequently selected factors (2.6\% and $1.2 \%$, respectively). Nearly a quarter of the respondents reported that they were motivated by the statement that owning an electric vehicle makes; however, less than 3\% ranked it as the primary reason they bought or leased an EV. 
Table 8: Selected and Priortized Motivations for Buying an EV

\begin{tabular}{|c|c|c|c|c|c|c|c|c|c|c|}
\hline \multirow[b]{4}{*}{$\begin{array}{l}\text { I wanted to reduce my driving's } \\
\text { impact on the environment }\end{array}$} & \multicolumn{10}{|c|}{ Percentages by Group } \\
\hline & \multicolumn{2}{|c|}{ All EV } & \multicolumn{2}{|c|}{$\mathrm{BEV}$} & \multicolumn{2}{|c|}{ PHEV } & \multicolumn{2}{|c|}{ Urban } & \multicolumn{2}{|c|}{ Rural } \\
\hline & Selected & $\begin{array}{c}\text { Ranked } \\
1 \text { st }\end{array}$ & Selected & $\begin{array}{c}\text { Ranked } \\
1 \text { st }\end{array}$ & Selected & $\begin{array}{c}\text { Ranked } \\
1 \text { st }\end{array}$ & Selected & $\begin{array}{c}\text { Ranked } \\
1 \text { st }\end{array}$ & Selected & $\begin{array}{c}\text { Ranked } \\
1 \text { st }\end{array}$ \\
\hline & 75.6 & 46.5 & 76.3 & 47.5 & 74.1 & 45.0 & 77.3 & 47.7 & 67.5 & 40.5 \\
\hline $\begin{array}{l}\text { I wanted to save on the cost of } \\
\text { fuel }\end{array}$ & 51.9 & 18.4 & 47.0 & 15.6 & 61.5 & 23.9 & 50.2 & 17.8 & 60.3 & 21.9 \\
\hline $\begin{array}{l}\text { I was interested in the new } \\
\text { technology }\end{array}$ & 41.4 & 11.0 & 43.3 & 12.1 & 37.4 & 8.8 & 41.5 & 10.6 & 41.0 & 12.8 \\
\hline $\begin{array}{l}\text { I wanted to reduce the amount of } \\
\text { oil imported into the USA }\end{array}$ & 31.2 & 4.2 & 32.4 & 4.4 & 28.7 & 3.6 & 31.5 & 4.3 & 28.9 & 3.7 \\
\hline $\begin{array}{l}\text { The federal tax incentives were } \\
\text { financially appealing }\end{array}$ & 27.3 & 5.1 & 22.5 & 3.2 & 37.1 & 9.0 & 26.8 & 4.9 & 29.4 & 5.8 \\
\hline $\begin{array}{l}\text { I liked the statement that owning } \\
\text { an electric vehicle makes }\end{array}$ & 23.1 & 2.9 & 24.5 & 2.9 & 20.4 & 2.7 & 23.5 & 2.8 & 21.6 & 3.3 \\
\hline $\begin{array}{l}\text { The lease deals were too good to } \\
\text { pass up }\end{array}$ & 14.5 & 5.2 & 18.0 & 6.5 & 7.8 & 2.4 & 14.6 & 5.2 & 13.9 & 5.2 \\
\hline Other & 14.1 & 5.4 & 16.3 & 6.6 & 9.7 & 2.9 & 14 & 5.4 & 14.6 & 5.2 \\
\hline $\begin{array}{l}\text { I had access to public charging } \\
\text { infrastructure at the places I go }\end{array}$ & 2.6 & 0.5 & 2.9 & 0.5 & 1.8 & 0.5 & 2.8 & 0.6 & 1.5 & 0.0 \\
\hline My workplace offered incentives & 1.2 & 0.2 & 1.1 & 0.2 & 1.5 & 0.3 & 1.4 & 0.3 & 0.5 & 0.0 \\
\hline $\mathrm{n}$ & 3288 & 3251 & 2181 & 2161 & 1086 & 1070 & 2731 & 2703 & 547 & 538 \\
\hline
\end{tabular}

Note: Bold indicates significant differences between groups based on a chi-squared test ( $p<.05)$; values being compared are color coded rowwise. 
When these results were disaggregated by EV type and land designation, significant differences between groups were highlighted; these differences are shown in Table 8. Urban residents, when compared to their rural counterparts, were significantly more likely to select and rank reducing their driving's impact on the environment as the primary motivation, although it was still the most commonly selected for all groups. Conversely, rural residents were far more likely to select and rank saving on the cost of fuel as their primary concern; this is likely related to their tendency to drive more miles in a typical day. There were numerous differences between the motivational factors selected by BEV and PHEV owners. PHEV owners were significantly more likely to select and rank saving on the cost of fuel and the financial appeal of the federal tax incentives as primary reasons. Significantly greater proportions of BEV owners selected wanting to reduce the amount of oil imported into the USA, liking the statement that owning an EV makes, interest in the new technology, and the appeal of lease deals as an important motivator; the latter two factors were also significant when looking at the differences in proportions of respondents who ranked them as the primary motivator.

Current EV owners and leasers were asked about their concerns related to buying and owning an EV. Respondents' pre-purchase and post-purchase concerns will be discussed in turn and then they will be compared to highlight any changes. First, respondents were asked, "Before you purchased an electric vehicle, what were your top three concerns about electric vehicles?” They were provided 11 prescribed concerns to choose from and given the option to select "other" and explain their concern. The results from this question are presented in Table 9. The most commonly selected concerns were, "The battery range being insufficient to get to the places I need to go" (58.6\%), "The performance of the battery over the life of the vehicle" $(40.7 \%)$, and "Running out of charge and getting stranded" (37.2\%). The former of those concerns was also most commonly selected as the most important concern; however, with regards to primary ranking, the latter two were surpassed by two options less likely to be selected overall, "The cost to purchase/lease an electric vehicle" and "The amount of time it takes to charge the battery." The least chosen prescribed concerns were the cost of charging (6.6\%) and the cost of maintenance $(6.0 \%)$.

Disaggregating the data by EV type and land designation surfaced numerous differences between the groups. Results indicate significant difference between reported concerns between PHEV and BEV owners for each of the prescribed pre-purchase concerns except for, "Installing and maintaining home charging equipment.” Most notably, BEV owners were significantly more likely to select and rank both concerns about battery range as their primary concern for purchasing an EV. On the other hand, PHEV owners were significantly more likely to select and 
Table 9: Selected and Priotized Concerns Before Purchasing an EV

\begin{tabular}{|c|c|c|c|c|c|c|c|c|c|c|}
\hline \multirow[b]{5}{*}{$\begin{array}{l}\text { The battery range being } \\
\text { insufficient to get to the places I } \\
\text { need to go }\end{array}$} & \multicolumn{10}{|c|}{ Percentages by Group } \\
\hline & \multicolumn{2}{|c|}{ All EV } & \multicolumn{2}{|c|}{$\mathrm{BEV}$} & \multicolumn{2}{|c|}{ PHEV } & \multicolumn{2}{|c|}{ Urban } & \multicolumn{2}{|c|}{ Rural } \\
\hline & & Ranked & & Ranked & & Ranked & & Ranked & & Ranked \\
\hline & Selected & $1 \mathrm{st}$ & Selected & $1 \mathrm{st}$ & Selected & $1^{\text {st }}$ & Selected & $1 \mathrm{st}$ & Selected & $1 \mathrm{st}$ \\
\hline & 58.6 & 31.0 & 65.5 & 35.8 & 44.9 & 21.7 & 59.1 & 31.1 & 56.7 & 30.9 \\
\hline $\begin{array}{l}\text { The performance of the battery } \\
\text { over the life of the vehicle }\end{array}$ & 40.7 & 11.5 & 38.7 & 10.3 & 44.8 & 14.1 & 40.0 & 11.6 & 44.2 & 11.0 \\
\hline $\begin{array}{l}\text { Running out of charge and getting } \\
\text { stranded }\end{array}$ & 37.2 & 14.5 & 45.1 & 16.7 & 21.3 & 10.2 & 37.9 & 15.1 & 34 & 11.5 \\
\hline $\begin{array}{l}\text { The cost to purchase/lease an } \\
\text { electric vehicle }\end{array}$ & 35.4 & 18.7 & 31.2 & 16.1 & 43.6 & 23.9 & 35 & 18.0 & 37.9 & 22.5 \\
\hline $\begin{array}{l}\text { The amount of time it takes to } \\
\text { charge the battery }\end{array}$ & 33.5 & 13.7 & 35.2 & 5.9 & 30.2 & 4.6 & 34.7 & 5.9 & 27.5 & 3.4 \\
\hline The cost of replacing the battery & 23.6 & 5.6 & 20.1 & 3.9 & 30.1 & 8.6 & 22.8 & 5.6 & 27.5 & 5.8 \\
\hline Public charging infrastructure & 21 & 3.9 & 24.5 & 4.3 & 14.1 & 3.2 & 21.2 & 3.9 & 19.9 & 3.7 \\
\hline The vehicle's resale/trade-in value & 10.2 & 2.3 & 8.6 & 2.1 & 13.5 & 2.6 & 10.4 & 2.3 & 8.9 & 1.9 \\
\hline $\begin{array}{l}\text { Installing and maintaining home } \\
\text { charging equipment }\end{array}$ & 9.8 & 1.5 & 9.1 & 1.2 & 11.2 & 2.2 & 9.7 & 1.5 & 9.7 & 1.7 \\
\hline The cost of charging & 6.6 & 1.6 & 4.6 & 1.1 & 10.4 & 2.7 & 6.4 & 1.5 & 7.4 & 2.2 \\
\hline The cost of maintenance & 6.0 & 1.3 & 2.9 & 0.6 & 11.9 & 2.6 & 5.3 & 1.0 & 9.1 & 2.6 \\
\hline Other & 4.4 & 2.2 & 3.5 & 1.7 & 6.3 & 3.1 & 4.4 & 2.2 & 4.8 & 1.9 \\
\hline $\mathrm{n}$ & 3230 & 3222 & 2145 & 2139 & 1066 & 1064 & 2683 & 2676 & 538 & 537 \\
\hline
\end{tabular}

Note: Bold indicates significant differences between groups based on a chi-squared test ( $p<.05) ;$ values being compared are color coded row-wise. 
rank the concern regarding the battery performance and all concerns regarding the costs associated with EVs (i.e., the cost to purchase or lease an EV, the cost of replacing the battery, the cost of charging, and the cost of maintenance). It is important to note that PHEV owners were significantly less concerned with the public charging infrastructure than BEV owners. It is highly possible that these significant disparities are in part due to the type of EV these respondents were considering buying. Differences in pre-purchase concerns between urban and rural residents were not as numerous; however, few key dissimilarities were highlighted. Rural residents were significantly more likely to select "The cost of maintenance" and "The cost of replacing the battery" and less likely to select "The amount of time it takes to charge the battery." Additionally, the proportion of residents who ranked "The cost to purchase/lease an electric vehicle" as their primary concern was significantly greater than that of the urban residents. Surprisingly, rural residents were significantly less likely to rank the concern of "Running out of charge and getting stranded" as a primary concern.

Post-purchase concerns about EVs were addressed by asking respondents "Now that you own an electric vehicle, what are your top three concerns?” Again, they were asked to rank their choices. Eleven prescribed concerns were provided along with the option to select "other" and this time they also had the option to select "I have no concerns." Results in Table 10 show that "The battery range being insufficient to get to the places I need to go" (35.3\%), "The performance of the battery over the life of the vehicle" (31.6\%), and "Public charging infrastructure" (29.4\%) are the top three most commonly selected post-purchase concerns. Concerns about the cost of charging and installing and maintaining home charging equipment were among the least commonly selected concerns (5.0\% and 3.5\%, respectively). Over a quarter of the respondents reported that they have no concerns; although it is not in the top three most commonly selected concerns, it is the second most ranked primary concern.

Disaggregating the results by EV type we see significant differences between BEV owners and PHEV owners for almost every concern. "The cost of owning/leasing an electric vehicle” was the only prescribed concern with no significant difference between the proportions of respondents who selected it or ranked it as the most important concern. The most significant difference was found in the concerns about battery range. The insufficiency of the batter range was the most commonly selected concern for BEV owners (43.9\%), but was among the least commonly selected concerns for PHEV owners (18.1\%). Similarly, BEV owners were far more likely to report worrying about running out of charge and getting stranded (24.0\%) than PHEV owners (3.2\%). Table 10 shows that there were also significant differences between these groups with respect to ranking these factors as the primary concern. Again, it is made evident that PHEV owners are considerably less concerned with public charging infrastructure. It is also important to note that PHEV owners were significantly more likely to select and rank having no concerns. It is likely that these disparities represent the functionality and differences of the two types of vehicles. Key differences between the concerns of urban and rural residents are also highlighted; rural residents were less likely to report that they are concerned with the battery range being insufficient to get to the places they need to go and that they worried about running out of charge and getting stranded. They were more likely than urban residents to select the concern about the performance of the battery over the life of the vehicle and the cost of maintenance. 
Table 10: Selected and Priortized Concerns After Purchasing an EV

The battery range being insufficient to get to the places I need to go

The performance of the battery over

the life of the vehicle

Public charging infrastructure

I have no concerns

The amount of time it takes to charge

the battery

The cost of replacing the battery

The vehicle's resale/trade-in value

Running out of charge and getting stranded

The cost of owning/leasing an

electric vehicle

The cost of maintenance

The cost of charging

Other

\section{Percentages by Group}

\begin{tabular}{|c|c|c|c|c|c|c|c|c|c|}
\hline \multicolumn{2}{|c|}{ All EV } & \multicolumn{2}{|c|}{$\mathrm{BEV}$} & \multicolumn{2}{|c|}{ PHEV } & \multicolumn{2}{|c|}{ Urban } & \multicolumn{2}{|c|}{ Rural } \\
\hline Selected & $\begin{array}{c}\text { Ranke } \\
\text { d 1st }\end{array}$ & Selected & $\begin{array}{c}\text { Ranked } \\
1 \mathrm{st} \\
\end{array}$ & Selected & $\begin{array}{c}\text { Ranked } \\
1 \mathrm{st} \\
\end{array}$ & Selected & $\begin{array}{c}\text { Ranked } \\
\text { 1st }\end{array}$ & Selected & $\begin{array}{c}\text { Ranked } \\
\text { 1st }\end{array}$ \\
\hline 35.3 & 20.5 & 43.9 & 25.9 & 18.1 & 9.4 & 36.0 & 20.8 & 31.5 & 18.9 \\
\hline 31.6 & 12.8 & 30.6 & 11.9 & 33.2 & 15.1 & 30.6 & 12.5 & 36.7 & 14.5 \\
\hline 29.4 & 11.4 & 31.1 & 11.5 & 26.3 & 11.1 & 29.5 & 11.3 & 29.3 & 12.0 \\
\hline 25.8 & 16.4 & 23.6 & 14.5 & 30.3 & 20.3 & 25.8 & 16.5 & 25.6 & 15.4 \\
\hline 22.0 & 6.9 & 22.1 & 6.2 & 22.0 & 8.5 & 22.3 & 7.3 & 20.6 & 4.6 \\
\hline 21.6 & 6.8 & 20.2 & 5.5 & 24.4 & 9.2 & 21.5 & 6.4 & 22.2 & 8.5 \\
\hline 17.9 & 7.7 & 16.0 & 6.4 & 21.7 & 10.6 & 17.5 & 7.5 & 20.0 & 8.5 \\
\hline 17.0 & 7.3 & 24.0 & 10.2 & 3.2 & 1.4 & 17.8 & 7.8 & 13.5 & 4.8 \\
\hline 5.4 & 2.7 & 5.1 & 2.6 & 6.1 & 2.7 & 5.4 & 2.7 & 5.7 & 2.7 \\
\hline 5.1 & 1.8 & 2.7 & 1.0 & 9.6 & 3.3 & 4.5 & 1.4 & 8.3 & 3.5 \\
\hline 5.0 & 1.5 & 3.7 & 0.9 & 7.8 & 2.8 & 5.0 & 1.4 & 5.2 & 1.7 \\
\hline 4.7 & 2.9 & 4.4 & 2.4 & 5.1 & 3.8 & 4.6 & 2.8 & 4.8 & 3.7 \\
\hline 3.5 & 1.2 & 2.6 & 0.9 & 5.4 & 1.8 & 3.6 & 1.3 & 3.3 & 0.6 \\
\hline 3238 & 2926 & 2148 & 1966 & 1070 & 943 & 2689 & 2436 & 540 & 482 \\
\hline
\end{tabular}

Installing and maintaining home

charging equipment

Note: Bold indicates significant differences between groups based on a chi-squared test $(p<.05) ;$ values being compared are color coded row-

wise. 

Urban residents were significantly more likely to rank "The amount of time it takes to charge the battery" as the primary concern. When comparing the pre-purchase and post-purchase concerns it became evident that respondents' concerns shifted dramatically after purchasing and operating an EV. Figure 14 depicts the changes in concerns about EVs from before purchasing an EV to after. Some concerns saw an increase in the proportion of respondents who selected that option. Less than $10 \%$ of the respondents listed the vehicles resale and trade-in value as a pre-purchase concern, but approximately $18 \%$ listed it as a post-purchase concern. Similarly, the concern about public charging infrastructure rose from $21 \%$ to nearly $30 \%$. However, most prescribed options saw a drop in the proportion of respondents reporting it as a concern. The concern about the cost of purchasing or leasing an EV saw the most dramatic decline, dropping from $35.4 \%$ pre-purchase to $5.4 \%$ post-purchase. The proportion of respondents concerned about the range of the battery and running out of charge both dropped by over $20 \%$. Concern about the performance of the battery over the life of the vehicle, the amount of time it takes to charge the battery, the cost of replacing the battery, and installing and maintaining home charging equipment all became less common after the purchase of an EV. These results and the considerable proportion of EV owners who reported having no concerns now that they own an EV may provide significant influential power for individuals considering purchasing an EV and those who have suppressed the option due to concerns.

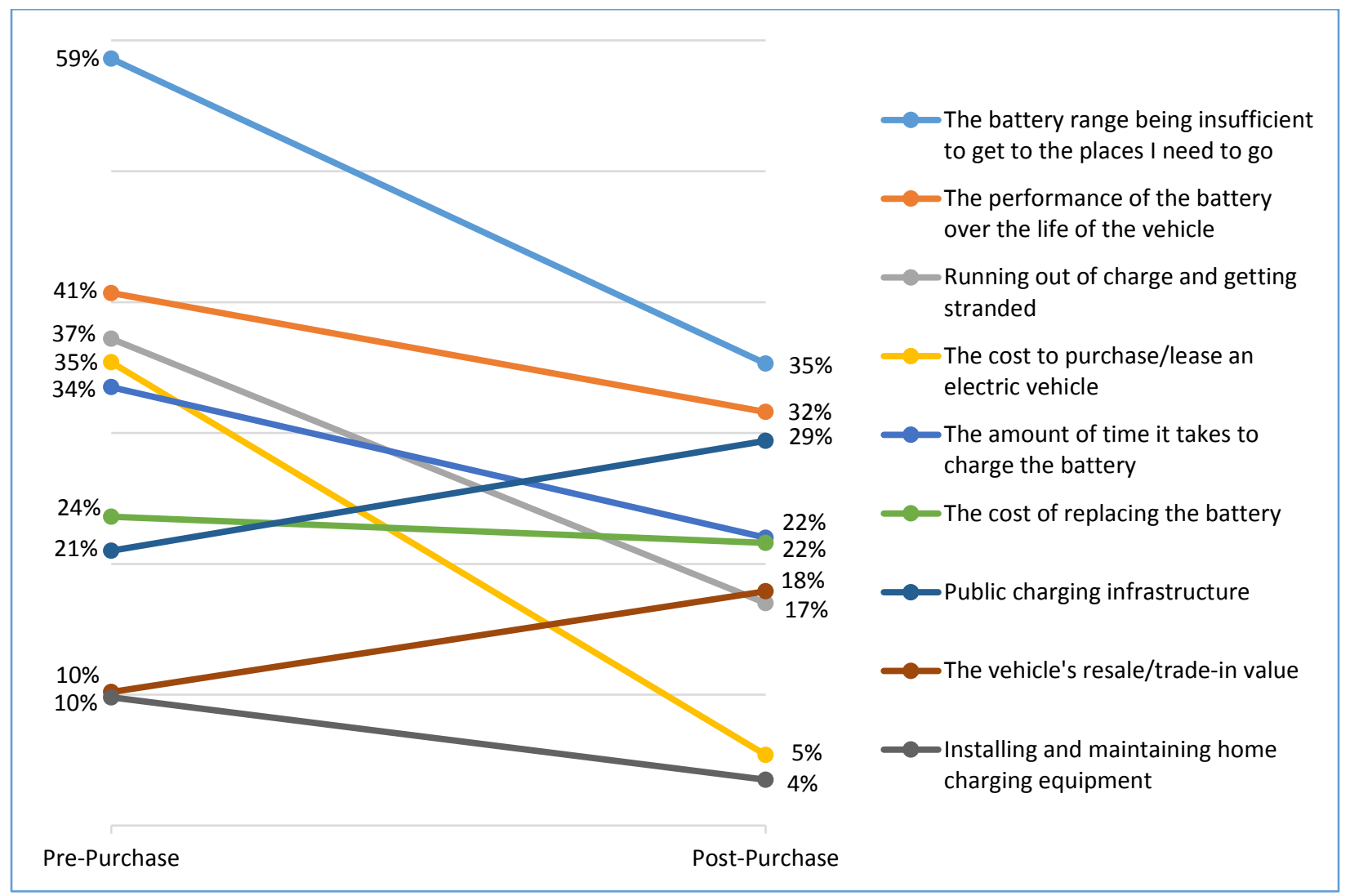

Figure 14: Comparing Pre- and Post-Purchase Concerns of EV Owners ( $n=3,230-38)$ 
The respondent's satisfaction with their EV is likely to impact whether or not they recommend EVs to friends, family, or colleagues considering purchasing a vehicle. To assess levels of satisfaction, EV owners were asked how satisfied they were with their EV overall and a variety of specific attributes; results to this question are presented in Figure 15. At least $50 \%$ of all respondents were satisfied or extremely satisfied (expressed hereafter as satisfied unless noted otherwise) with all of the attributes except for the vehicles performance on snowy or unpaved roads (48.7\%). Approximately $98 \%$ of EV owners were satisfied with the vehicles' performance, $96.3 \%$ with the vehicle overall, and $95.3 \%$ with the vehicles' acceleration and top speed. While respondents were more likely to be extremely satisfied with the vehicles' performance on snowy or unpaved roads than the vehicles' charging speed and the vehicles' electric range, the latter two had higher rates of overall satisfaction; these three attributes had the highest rates of dissatisfaction. While it appears that satisfaction tends to be similar between BEV owners and PHEV owners, there are a few differences worth noting. First, BEV owners were more likely to be satisfied with charging speed, passenger and cargo space, and acceleration and top speed. Second, PHEV owners were more likely to be satisfied with styling and electric range. Lastly, BEV owners were more likely to be extremely satisfied with the performance of the vehicle. A final set of questions asked respondents to indicate whether or not they agree with a variety of statements, which could influence theirs' and others' decision to purchase an EV in the future. When presented with the statement, "I would recommend electric vehicles to someone in the market for a new vehicle" $81.4 \%$ of the respondents agreed and an additional 14.9 percent somewhat agreed. Nearly $90 \%$ of respondents agreed that they would purchase or lease an electric vehicle again, with $7.1 \%$ reporting they somewhat agree. Lastly, $44.9 \%$ of respondents somewhat agreed or agreed with the statement, "I want to be one of the first to own new technology." Although these results are not representative of all EV owners, they do indicate a high level of satisfaction with EVs as well as a strong propensity for EV owners to purchase another EV in the future and recommend EVs to potential buyers. 


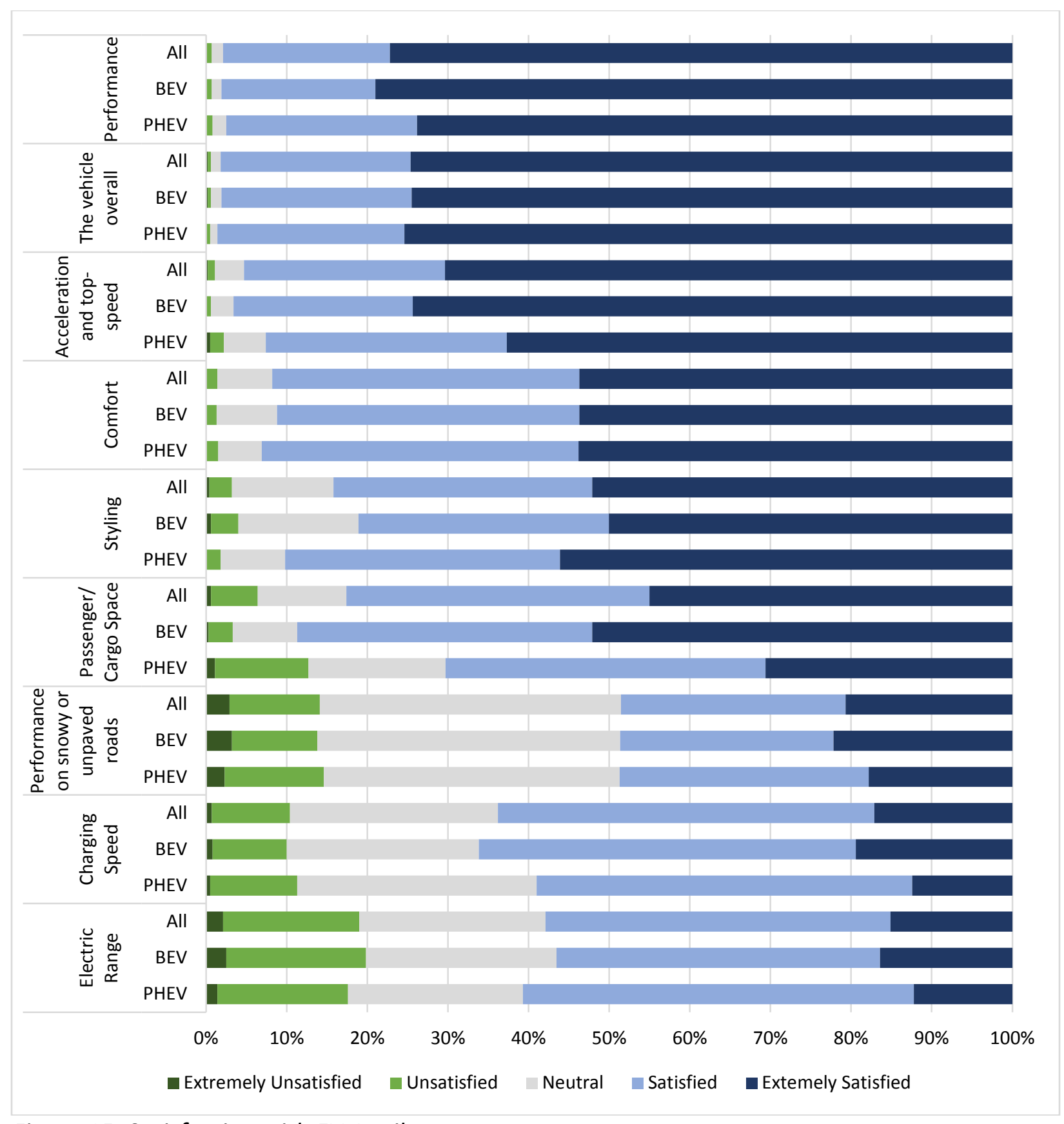

Figure 15: Satisfaction with EV Attributes 


\subsection{DISCUSSION}

The non-EV owners included in this study showed a fairly high degree of familiarity with EVs, and many reported that they have the desire to learn more. Approximately half of the respondents felt that EVs are convenient vehicles, and the vast majority were in favor of EVs replacing gas vehicles over time (82.3\%). An extended battery warranty, assistance with installing a home charger, and a tax rebate in lieu of a tax credit were the most commonly selected incentives that would increase non-EV owners' interest in purchasing or leasing an EV. However, the results indicate that within the existing conditions the average respondent's next vehicle is most likely to be a hybrid. Given the respondents' familiarity with EVs, it can be expected that some have considered purchasing an EV, yet their concerns have outweighed their motivations. Understanding this relationship is critical to enhancing rates of EV ownership.

Throughout this report we have treated EV owners and non-EV owners separately to assess disparities within those groups; however, comparing the two groups could be useful for valuing non-EV owners' propensity to purchase an EV and advocating for EVs. In this section we will discuss the key findings of the study in addition to comparing the results from the two samples. The results presented in this report have illuminated the key reasons why non-EV owners might consider purchasing or leasing an EV as well as the key motivating factors for those who already have. Figure 16 shows the proportion of respondents who selected each of the motivators as one of their three choices. For both EV and non-EV owners the desire to reduce their driving's effect on the environment was by far the most commonly selected option, followed by the desire to save costs on fuel. The third most commonly selected motivator is where we start to see a difference between the two groups; for EV owners the interest in new technology was the third most common choice and for non-EV owners it was the desire to reduce the amount of oil imported into the USA. Non-EV owners were less likely to select the financial appeal of the lease deals as a top motivating factor, yet they were more likely to cite having access to public charging infrastructure at the places they visit often. Both EV owners and non-EV owners were least likely to report that they were motivated by an incentive offered by their workplace. Although there were a few slight differences between the groups, motivations tend to be fairly similar between EV owners and those who own a hybrid or ICE vehicle. 
I want/wanted to reduce my driving's effect on the environment

I want/wanted to save money on the cost of fuel

I am/was interested in the new technology

I want/wanted to reduce the amount of oil imported into the USA

The federal tax incentives are/were financially appealing

I like/liked the statement that owning an electric vehicle makes

The lease deals for electric vehicles are/were too good to pass up

I have/had access to public charging infrastructure at the places I go

My workplace offers/offered incentives
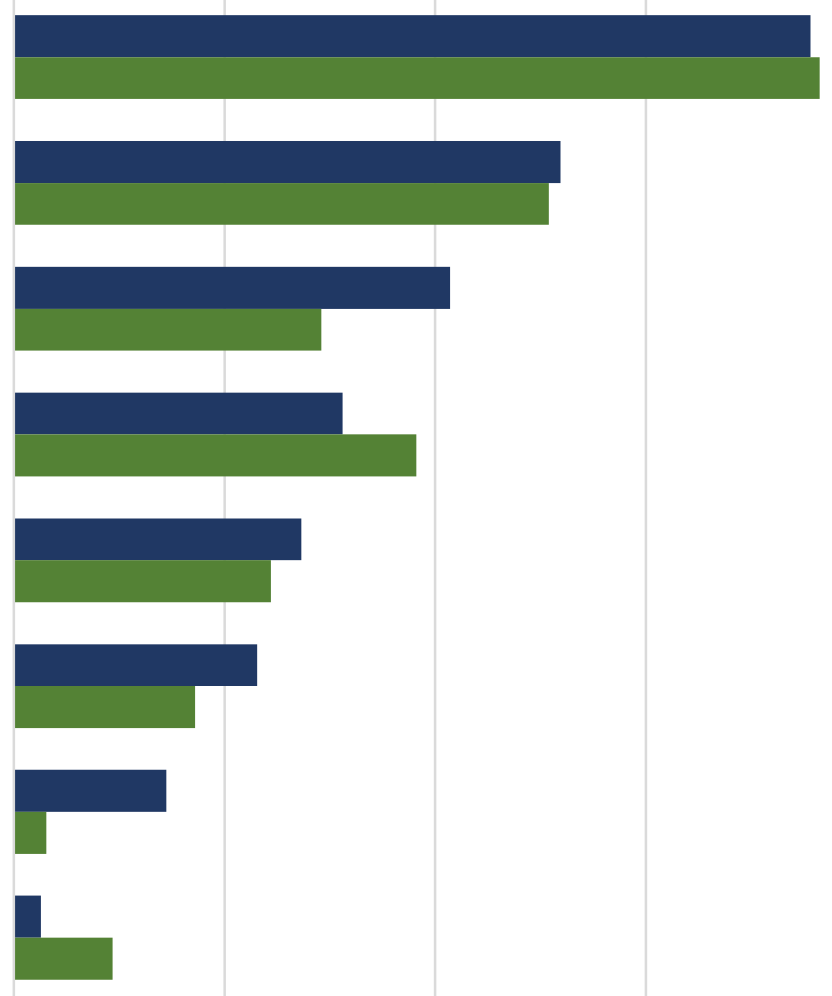

।

$0 \%$

$20 \%$

$40 \%$

EV Non-EV

Figure 16: Motivations of Non-EV owners and EV-Owners Compared

Disaggregating the motivations of EV owners by vehicle type (PHEV and BEV) and land designation (urban and rural) highlighted interesting differences. PHEV owners were significantly more likely than BEV owners to cite saving on the cost of fuel and the financial appeal of the tax incentives as the most influential motivator. On the other hand, BEV owners were significantly more likely to be motivated by their interest in new technology and the attractive lease deals. Urban and rural residents were quite similar in their ranking of the prescribed motivations; however, rural residents were significantly less likely to list reducing their driving's impact on the environment as their primary motivator. This was also the case when comparing urban and rural residents from the non-EV sample. Non-EV rural respondents were also less likely to be influenced by the hopes of reducing the amount of oil being imported into the United States.

The survey results have also provided important information regarding the concerns about EVs from the perspectives of both EV and non-EV owners. Figure 17 depicts the similarities and differences between the groups' concerns. The top three concerns for non-EV owners were 
battery range, running out of charge and getting stranded, and insufficient public charging infrastructure. For EV owners (pre-purchase) the top three concerns were battery range, battery longevity, and running out of charge and getting stranded. Furthermore, both groups were least likely to cite concerns about the vehicle's resale value and installing home charging equipment. Although there are some slight differences, the two groups prioritized similar concerns. These similarities are important when assessing the shift in concerns after EV owners purchased or leased their vehicle. The top three pre-purchase concerns, all of which relate to range anxiety or battery longevity, dropped by significant numbers post-purchase. On the other hand, concerns that were less important, such as public charging infrastructure and low resale values, increased considerably. These findings indicate that initial concerns about battery range and longevity may be unjustified, but factors that may not be considered by the typical consumer may in fact become more of a concern. These relatively dramatic shifts in concerns have implications for both potential consumers, distributors, and public policy. The considerable decrease in primary concerns could be a useful illustration for those who may be deterred from buying an EV due to concerns about battery range and longevity. The increase in concerns regarding charging infrastructure indicate that measures should be taken to enhance public charging and assist consumers with identifying locations to charge. The former improvement is especially important for individuals lacking the ability to charge at home. While the majority of respondents in this sample lived in a single-family detached home with the option to charge, many urban residents who rely on street parking may not have access to secure charging; thus, owning and operating an EV for daily mobility needs may not be feasible.

Disaggregating EV owners' concerns by vehicle type revealed that the concerns considered by PHEV and BEV owners differ significantly. PHEV owners were two times less likely than BEV owners to select "running out of charge and getting stranded" as an important pre-purchase concern and eight times less likely to cite it as a post-purchase concern. PHEV owners were also significantly less likely to report concerns about battery range and public charging infrastructure; when combined these results are representative of the vehicles' differential capabilities. Furthermore, PHEV owners were significantly more likely to report that they had no concerns post-purchase, despite fairly similar satisfaction rates (refer to Figure 15). These findings are useful for informing individuals about what type of EV would be most conducive for their driving habits. They are also indicative of the disproportionately higher percentage of rural residents with PHEVs. Interestingly, rural residents were significantly less likely to cite range anxiety and getting stranded as important post-purchase concerns despite traveling significantly further distances in a typical day. This finding may be partially explained by their tendency to rely on their EV less frequently than urban residents; rural residents were far less likely to utilize their EV for $100 \%$ of their weekly driving and more likely to rely on hybrid and gas vehicles. 


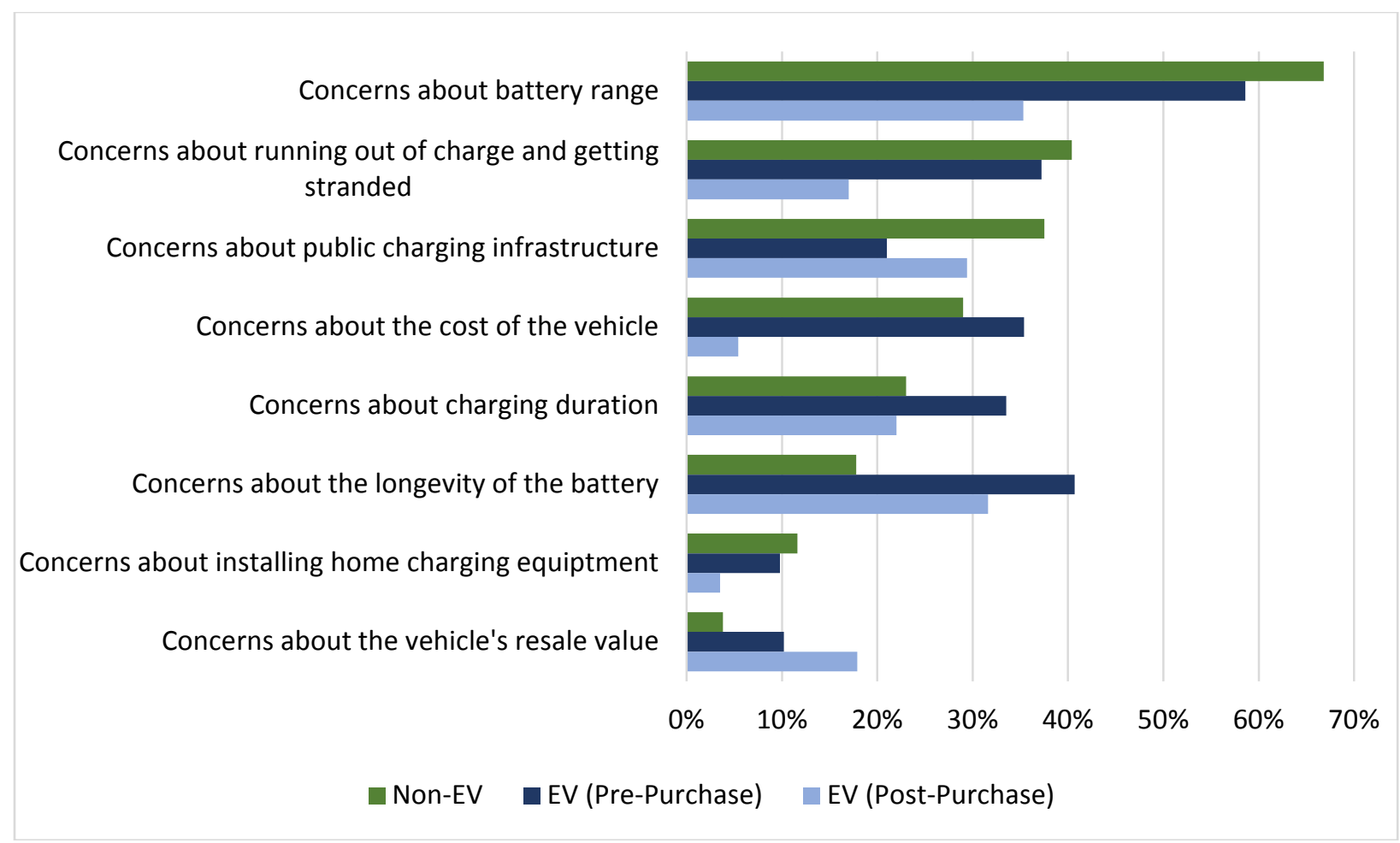

Figure 17: Comparing the Concerns of Non-EV Owners to Those of EV Owners

(Note: These concerns were reworded to better represent the options provided to both samples - Refer to Table 5, Table 9, and Table 10) 


\subsection{CONCLUSION}

The findings of this study can be a useful tool in how to inform hybrid owners and other populations who may be considering an EV that many of their concerns, such as battery range and longevity, charging time and costs, are unlikely to be realized. The study could also inform advocacy groups and educational programs. The results could help consumers choose the most appropriate type of EV based on their driving habits and housing status. However, while some concerns may be ill-informed, other seemingly benign concerns may be enhanced, such as concerns about public charging infrastructure and the resale value of the vehicle. These issues require the attention of local governments and EV distributors. In order to increase the propensity to purchase an EV, especially for those without access to charging at home, there is a need to enhance the existing infrastructural conditions. Furthermore, public policies should promote programs which provide information, guidance, and support to consumers.

This study also indicates that EV owners in Oregon are predominately white, well-educated, and affluent. African-Americans account for a low .05\% of all EV respondents, compared to a 2.1\% share of Oregon's population (U.S. Census, 2016). The percent of respondents living in households making less than $\$ 35,000$ a year is extremely low (4.2\%). In order for EVs to gain widespread acceptance, there is a necessity to endorse outreach and awareness programs in lowincome minority communities and provide incentives to support socioeconomically disadvantaged households. Future research could provide important insight into the social and economic barriers to purchasing an EV. Other avenues for research include exploring the rather dismal presence and influence of work incentives, examining the changes in travel behavior before and after purchasing an EV, and investigating the significance of EVs in rural households. While it is likely that EV owners will continue to recommend EVs to others and that they themselves will choose an EV over a gas vehicle in the future, there is a considerable amount of effort needed to enhance EV ownership rates outside of the socioeconomically advantaged and eco-friendly populations. This report provides evidence to inform EV advocacy and outreach and has highlighted the barriers which need the most attention in order for the EV market to expand at a greater rate. 


\subsection{REFERENCES}

1. Insideevs.com. "December 2017 Plug-In Electric Vehicle Sales Report Card.” https://insideevs.com/december-2017-plugin-electric-vehicle-sales-report-card/

2. Alliance of Automobile Manufacturers. "Advanced Technology Vehicle Sales Dashboard.” https://autoalliance.org/energy-environment/advanced-technology-vehiclesales-dashboard/

3. Oregon DOT. "Oregon DMV Vehicle Registration Statistics." http://www.oregon.gov/ODOT/DMV/docs/2017_Vehicle_County_Registration.pdf

4. Alliance of Automobile Manufacturers. "2016 State Facts: Autos drive Oregon forward." https://autoalliance.org/in-your-state/OR/pdf/?export

5. U.S. Energy Information Administration (2016) https://www.eia.gov/electricity/state/oregon/

6. Oregon DEQ. “Zero Emissions Vehicles.” http://www.oregon.gov/energy/energyoregon/Pages/Zero-Emissions-Vehicles.aspx

7. Oregon DEQ. "Zero Emission and Electric Vehicle Rebate Program: Phase 1 Application.” http://www.oregon.gov/deq/FilterDocs/zev-faq.pdf

8. Plugshare. https://www.plugshare.com/Assessed March 1, 2018. 

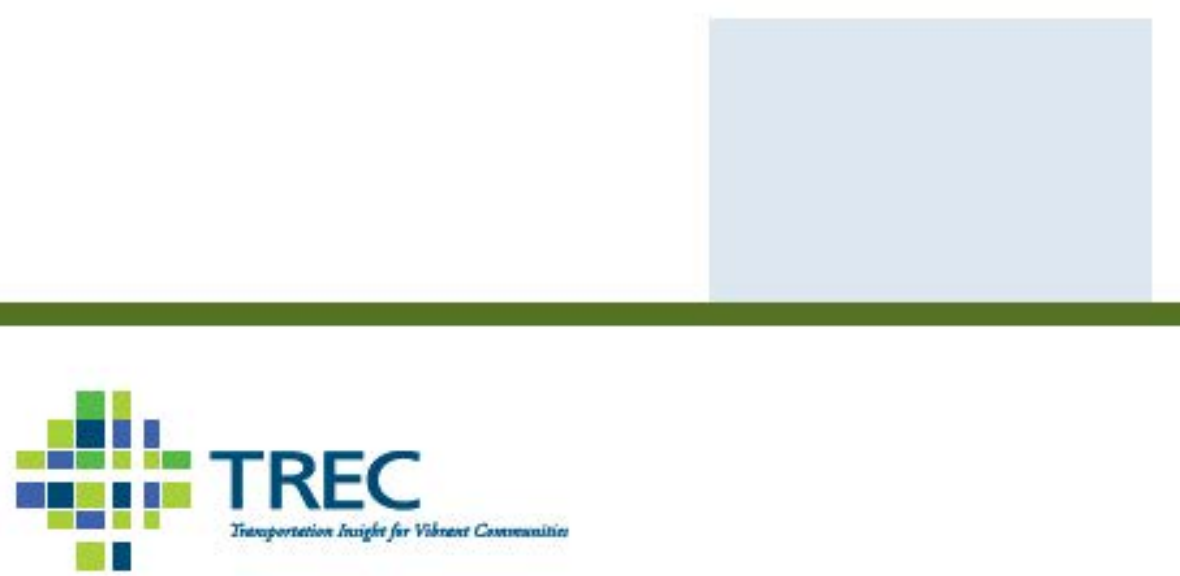

Portland State University

1900 S.W. Fourth Ave،, Suite 175

Portland, OR 97201 